Rhode Island College

Digital Commons @ RIC

Master's Theses, Dissertations, Graduate Research and Major Papers Overview

5-14-2021

\title{
A Resource Nurse in the Community: An Evaluation of Role Implementation
}

Michelle Bull

Follow this and additional works at: https://digitalcommons.ric.edu/etd

Part of the Nursing Commons

\section{Recommended Citation}

Bull, Michelle, "A Resource Nurse in the Community: An Evaluation of Role Implementation" (2021). Master's Theses, Dissertations, Graduate Research and Major Papers Overview. 396.

https://digitalcommons.ric.edu/etd/396

This Project Paper is brought to you for free and open access by Digital Commons @ RIC. It has been accepted for inclusion in Master's Theses, Dissertations, Graduate Research and Major Papers Overview by an authorized administrator of Digital Commons @ RIC. For more information, please contact digitalcommons@ric.edu. 
A Resource Nurse in the Community: An Evaluation of Role Implementation

A Scholarly Project Submitted in Partial Fulfillment of

The Requirements for the Degree of

Doctor of Nursing Practice

in

The School of Nursing

Rhode Island College

May 14, 2021

by

Michelle Bull, MSN, RN, CNL 


\section{Acknowledgements}

The process of obtaining my Doctor of Nursing Practice (DNP) has been a journey of persistence and grit. What I have learned through this journey is to never give up on your dreams. Turn your goals into action plans and make them happen. I became a nurse because I wanted to help others and fulfill my duty to do so to the best of my ability. My DNP project was the pinnacle of this vision. Helping others and bringing the nurse's role to the forefront of a community was a vision that was made possible through the completion of this project.

I want to begin my acknowledgments by acknowledging my mentor and faculty advisor, Dr. Lynn Blanchette. Dr. Blanchette helped provide a consistent vision for me that assisted with completing my project through many months. My family, husband, Brant A Bull, children Brandon and Elizabeth Bull, and my parents Robert and Mary Morneau. My family gave me the support needed to dedicate my time towards completing my degree.

I want to thank the community collaborators in Stonington, CT, including The Yellow Farm House Education Center, Stone Acres Farm, and the Department of Human Services in Stonington. I would be remiss not to mention my colleagues that worked alongside me during this journey, Dr. Keith Scally, Dr. Leanne Burke, and Dr. Lisa Connelly. The faculty at Rhode Island College, including Dr. Justin DiLibero, Dr. Debra Servello, and Dr. Jean Salera-Vieria, for the ongoing support.

It takes a village to build something, and without that support, I would not be here today. Thank you all for your belief in me during this journey. 


\begin{abstract}
Background: Children who live in low-income households are more likely to develop childhood obesity-related to low food security and lack of access to healthier foods (Lee \& Lim, 2009; Sage, McCracken, \& Sage, 2013). Health promotion efforts that focus on family interventions are successful in combating childhood obesity (Jang\& Whittemore, 2015; Ordway, et al., 2018). The role of the nurse can be positioned to facilitate health promotion interventions in the community setting.
\end{abstract}

Purpose/Specific Aims: The purpose of this project was to evaluate a pilot intervention using a nurse as a resource in a local community working with families in a low-income setting by connecting them to resources to facilitate healthier habits.

Methods: The resource nurse implemented an evidence-based program focused on healthy habits and ensured that healthy produce was available to all participants enrolled. Throughout the program, the resource nurse followed the families weekly to monitor the program's progress and evaluate for resources needed for successful completion of the program. Food security rates were measured pre and post-program using the USDA food security questionnaire, measurement of nurse hours and rates of participation with the program was collected. In addition, qualitative feedback was collected on participant experiences by the resource nurse.

Results: Weekly participation rates in the program increased over the course of the program. Food security rates for families with baseline food insecurity increased significantly over the course of the program. Qualitative themes showed the role of the nurse being instrumental in providing connections, support, and education.

Conclusion: Results demonstrate statistical significance in improving food security rates for families that were identified as food insecure preprogram. Clinical significance is demonstrated in the qualitative data that highlight the role of the resource nurse in making a significant impact in the lives of the participants during the program.

Key Words: Resource Nurse; Food Security; Childhood Obesity; Community; Connections; Support; Education 


\section{Table of Contents}

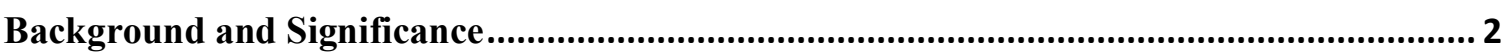

Problem Statement and Study Question ............................................................................... 3

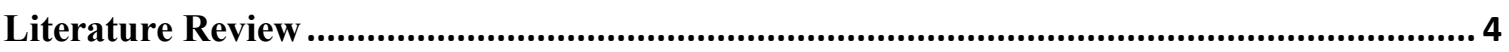

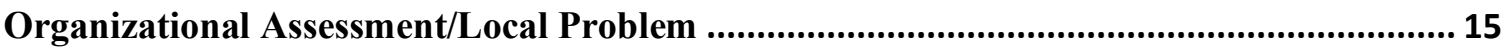

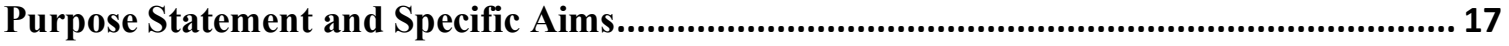

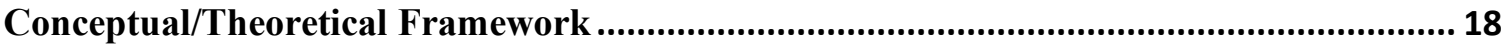

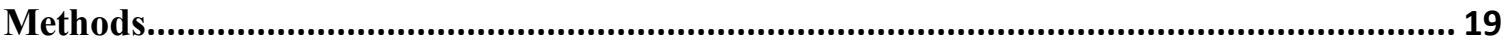

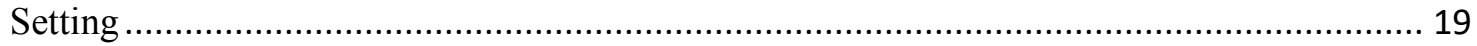

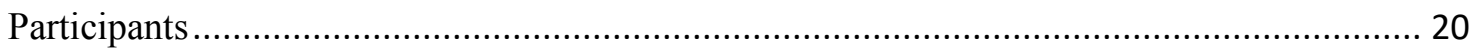

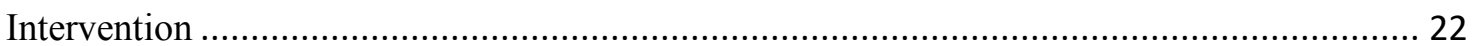

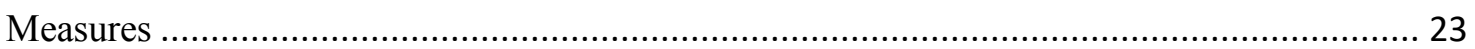

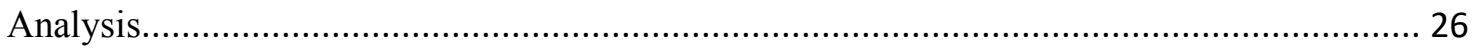

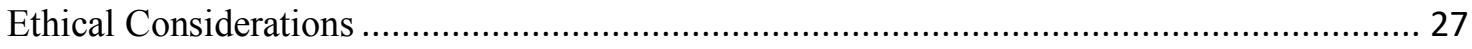

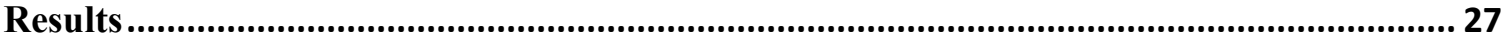

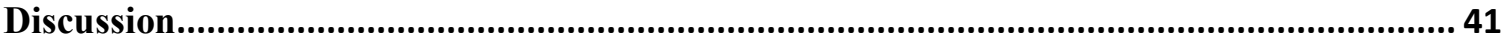

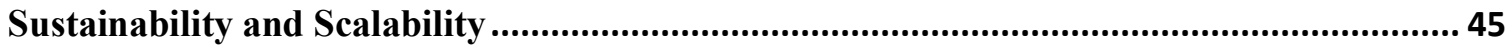

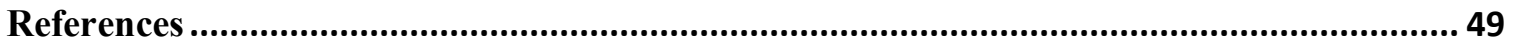

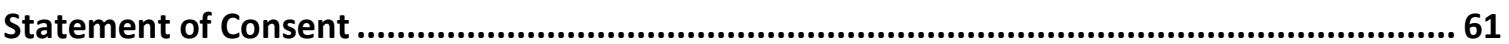

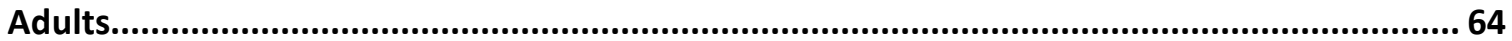

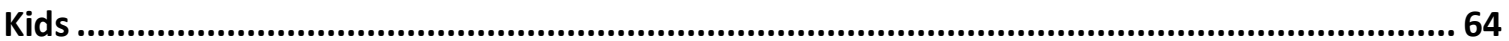


A RESOURCE NURSE IN THE COMMUNITY: AN EVALUATION OF ROLE IMPLEMENTATION

Rising rates of childhood obesity have tripled since the 1970s (CDC, 2019). As

adults, these children will continue to struggle with obesity and chronic illnesses.

Obesity-related diseases include the development of chronic diseases, including diabetes and cardiovascular disease. Social determinants of health indicate that populations in lower socioeconomic status groups have higher obesity rates as a population (CDC, 2019). Food insecurity in the United States is a problem faced by many low-income households, leading to obesity.

Upstream thinking for the prevention of childhood obesity focuses on population health and is supported by environmental changes. Understanding conditions in the environment, which cause obesity is the first step in combating the childhood obesity epidemic. Research demonstrates the connection between a lack of food resources in lower socioeconomic groups and obesity. Creating resources, specifically nursing resources accessible to all populations, can be a primary step towards fighting the obesity epidemic.

This project describes a pilot intervention that utilized a resource nurse who identified a need for social supports surrounding healthy living, and worked with selected families in a community. The project highlights the connections between resource allocations in the community and the resource nurse's ability to help families sustain more beneficial living practices. 


\section{Background and Significance}

Rising rates of childhood obesity in the United States is a growing national public health crisis (Karnik \& Kanekar, 2012). The 2015-2016 National Health and Nutrition Survey reported a $20.6 \%$ obesity prevalence rate in children aged $12-19$ years of life (CDC, 2017). If an individual is overweight in adolescence, there is a $70 \%$ chance that they will remain overweight or obese as an adult (Simmonds, Llewlynn, Owen \& Woolacott, 2015). Health consequences related to childhood obesity are widespread and include increased asthma, fatty liver disease, orthopedic problems, sleep apnea, Type II diabetes, and increased cardiovascular risk. Mental health risks include increased risk for bullying, depression, and suicide (NCCOR, 2020).

Obesity prevalence increased by $23-33 \%$ for children in low education, low income, and higher unemployment households between 2003-2007 (Rogers et. al, 2015). Low-income communities face a host of barriers to improving health statuses (Rogers et al., 2015). Children living in low-income households face a myriad of conditions that can lead to stress. Lower socioeconomic groups have a higher rate of food insecurity. Food insecurity can place families under pressure, leading to the selection of foods that are less healthy, cheaper and easier to attain, (Lohman et al., 2009). Food insecurity in the United States is a problem faced by many low-income households. Food insecurity can lead to the development of chronic diseases such as obesity. It is estimated that $10.5 \%$ of U.S. households were food insecure at some point during 2019, meaning that they lacked access to enough food for an active, healthy lifestyle for all household members (United States Department of Agriculture (USDA) Economic Research Service, 2020). 
Childhood obesity is a multi-factorial problem and should not only be examined at the individual level but additionally through the lens of a public health perspective. Environmental factors, lifestyle preferences, and cultural environment all play a role in rising rates of childhood obesity (Karnik \& Kanekar, 2012). Health promotion efforts at the individual and population-based level can have a significant impact on childhood obesity. Healthy People 2030 (HP2030) has set a goal to reduce overweight and obesity by helping people eat healthy and get physical activity. Additionally, an objective is to reduce the proportion of children and adolescents with obesity (Office of Disease Prevention \& Health Promotion, 2020). Reducing the epidemic of childhood obesity requires going beyond the individual health promotion level. The battle to curb childhood obesity is tied to national, state, community, neighborhood, and household efforts to change modifiable risks that enable positive health changes (Rogers et al., 2015). Connecting the public to resources in the community and assisting with initiatives is a key aspect in intervention-based care focused on healthy living behaviors.

\section{Problem Statement and Study Question}

It is documented that childhood obesity rates have risen dramatically over the last few decades (CDC, 2019). Obesity has been linked to several long-term consequences, including chronic illness and psychological damage (Lohman, Baur, \& Uuay, 2004; NCCOR, 2020, Rogers et al., 2013; Sahoo et al., 2015). Literature searches focusing on research regarding childhood obesity have, in the majority, focused on causation and proper management of the condition (Anderson \& Butcher, 2006; Sahoo et al., 2015). Children from lower socioeconomic backgrounds are disproportionally affected by obesity (Lee \& Lim, 2009; Lobstien, Baur, \& Uuay, 2004; Lohman et al., 2009; Rogers et 
al., 2013). The official poverty rate in the United States in 2019 was $10.5 \%$, or 34 million people living in poverty (United States Census Bureau, 2020). In 2020, the United States was affected by the COVID 19 pandemic that negatively affected the nation's poverty rates. About 24 million adults (11\% of all adults) in the United States reported that their households did not have enough food to put on their tables weekly at some point in 2020 . Families with children were more likely to report having insufficient food to eat in 2020 (Center on Budget and Policy Priorities, 2020).

The project utilized the role of a resource nurse. Using a resource nurse's role in the setting of public health setting was exploratory. The aim of the role was to create a position within the community that provides families with education around healthy living behaviors and leverages nursing knowledge to connect families with appropriate community resources to facilitate the achievement of sustainable behavior changes. The question that the project will answer is how the role of a resource nurse using an evidenced based intervention aimed at increasing healthy living behaviors and providing connections to community resources can increase the sustainability of healthy living practices over three months with families.

\section{Literature Review}

Obesity in America is a predominant health risk factor for many chronic health issues that lead to morbidity (Sahoo et al, 2015). Rates of pediatric obesity have tripled in the last three decades, making it a national health concern (NCCOR, 2020). Healthy People 2030 aims to improve the nation's health by identifying top health indicators that lead to poor health. One of the main goals of Healthy People 2030 is to increase the health of all Americans (Office of Disease Prevention and Health Promotion, 2020). 
Chronic health conditions are reduced by taking primary health measures to decrease obesity (NCCOR, 2020). An objective of HP2030 is to reduce overweight and obesity by helping people eat healthy and get physical activity. About one in five children and adolescents in the United States have been identified as being overweight and/or obese, which is $17.8 \%$ of children aged 2-19 years between 2013-2016 that were obese (Office of Disease Prevention and Health Promotion, 2020). An objective of HP2030 is to reduce the proportion of children and adolescents with overweight and obesity to at least $15.5 \%$ or lower (Office of Disease Prevention and Health Promotion, 2020). Evidence has suggested that using one or more behavioral strategy is an effective way to reduce childhood obesity (Cohen, Gottlieb \& Underwood, 2001; Kitzmann, Dalton, \& Buscemi, 2008). Additionally, using culturally appropriate public health interventions can make it easier for people to achieve healthy living goals (Office of Disease Prevention and Health Promotion, 2020).

Pediatric obesity is defined by measuring body mass index (BMI). A person's weight calculates BMI in kg divided by the height in meters squared. In children, BMI is age and gender-specific and referred to as a BMI for age, and body fat changes in development with height and weight (CDC, 2019). In children, BMI is expressed as a percentile obtained by plotting results in a standardized graph. The standardized charts are based on data from national surveys of children between the 1960s and 1980s. A BMI of $85 \%$ to $95 \%$ as a child is considered overweight; a BMI of over $95 \%$ is deemed to be obese (CDC, 2019). Pediatric obesity rates have risen dramatically in the last few decades, particularly among low-income families and individuals (Lee, 2011; Wang, 2011). 
Health consequences of childhood obesity can last into adulthood. An obese teenager has up to an $80 \%$ chance of becoming an obese adult, and being overweight and obese causes a $60 \%$ increased risk of developing asthma and a fourfold greater risk of developing Type II diabetes (NCCOR, 2020; Abbasi, Juszczyk, Jarrseveld, \& Gulliford, 2017). Causes of childhood obesity are related to energy imbalances, meaning more calories are taken in than expelled. A myriad of factors can create an imbalance in calorie expenditure which can be caused by environmental factors (Anderson \& Butcher, 2006). Overweight adolescents consume more than 700-1,000 more calories per day than what is needed for growth (Jones, Al-Khidairy, Melendez-Torres, \& Oyebode, 2018). A study of the effect of the influence of the home environment on the development of obesity in children showed that maternal obesity, low family incomes, and lower cognitive stimulation have significantly elevated risks of the development of childhood obesity (Ordway et al, 2018). However, efforts to prevent obesity are positively enhanced by parental education programs that encourage more stimulating home environments (Strauss,\& Knight, 1999). Problematic social trends to influence the rise of childhood obesity include use of motorized transports, increase traffic hazards that impede outside activity, decreased recreational time in schools, increased sedentary recreation including video games and media, greater quantities of dense caloric foods available, increased fast food opportunities, and rising use of sugary drinks (Lee \& Lim, 2009; Wolch et al, 2011). Targeting the rise of the social trends that promote obesity rates relies on the identification of awareness of the problem and targeting efforts to prevent it. Public funding that requires support at all levels ranging from the individual 
to the government is needed to be able to work together to combat the rise of an obesogenic environment (Lobstein, T., Baur, L., \& Uauy, R., 2004).

Over the last few decades, fewer children spend time outside related to distance, weather, fear of crimes, and inadequate space. Only $2.1 \%$ of high schools, $7.9 \%$ of middle schools, and $3.8 \%$ of elementary schools provide daily physical education (NCCOR, 2020). Health promotion strategies like having a healthy diet, regular physical fitness, and low BMI (body mass index) are preventive measures that will decrease the risk of Type II diabetes (CDC, 2017). The Youth Risk Behavior Surveillance System (YRBSS) and the Behavioral Risk Factor Surveillance System (BRFSS) are two data sources available through the CDC (Centers for Disease Control) that categorize numerous health data on youth and adults respectively on a national and state level. The survey is conducted periodically that monitors six categories of health-related behaviors that contribute to the leading cause of death and disability among youth and adults that include but are not limited to unhealthy dietary behaviors and inadequate physical activity. Data from the most recent YRBSS survey that was conducted in 2017 included a national survey of high school students as a cross sectional study (CDC, 2017).

Questions on the survey asked about engagement in certain risk behaviors and school and health programs' status to address those behaviors. Areas of research looked at obesity trends, dietary behaviors, perceived body image, and physical activity trends. Data collected over time helps track pediatric obesity trends over time (CDC, 2017). The survey in 2017 showed that a higher proportion of males $17.5 \%$ versus female $12.1 \%$ in grades 9-12 were defined as being over 95\% for BMI. A greater percentage of Black and 
Hispanic 18.2\% versus White 12.5\% were defined as having over 95\% BMI as well

(CDC, 2017). Please see Figure 1A below for a graphical representation.

Figure 1A

Percentage of High School Students Who Had Obesity* by Sex, ${ }^{\dagger}$ Grade $^{\dagger}{ }^{\dagger}$ and

Race/Ethnicity ${ }^{\dagger} 2017$

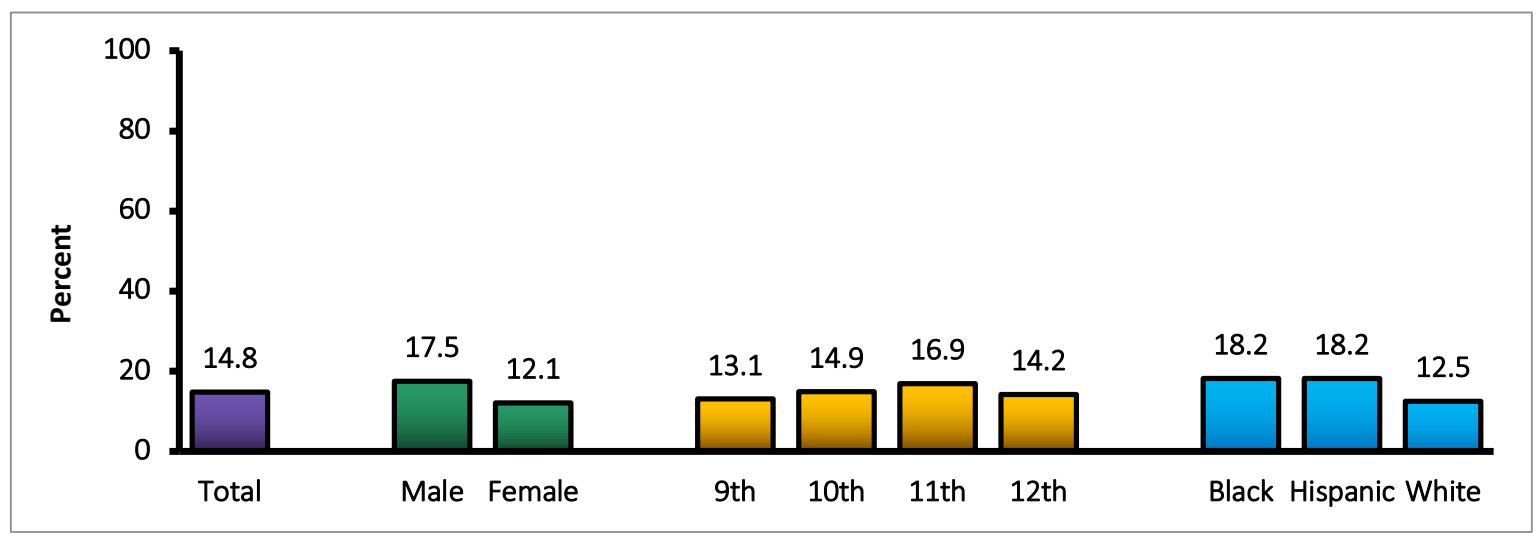

$\geq 95$ th percentile for body mass index, based on sex- and age-specific reference data from the 2000 CDC growth charts. In 2017, new, slightly different ranges were used to calculate biologically implausible responses to height and weight questions.

${ }^{\dagger} \mathrm{M}>\mathrm{F}$; 11 th $>9$ th, 11 th $>12$ th; $\mathrm{B}>\mathrm{W}, \mathrm{H}>\mathrm{W}$ (Based on t-test analysis, $\mathrm{p}<0.05$.

All Hispanic students are included in the Hispanic category. All other races are non-Hispanic.Note: This graph contains weighted results. Source: National Youth Risk Behavior Survey, 2017. 
Physical activity is another health behavior correlated with obesity. Current recommendations from the $\mathrm{CDC}$ recommend engaging in sixty minutes of moderate to heavy physical activity a day to maintain health (CDC, 2017). The YRBSS survey asked high school students about the amount of physical activity they engaged in daily. The survey showed that $15.4 \%$ of high school students between grades 9-12 did not engage in at least 60 minutes of physical activity daily. The percentages were higher for females at $19.5 \%$ than males at $11 \%$. Additionally, Black and Hispanic children had higher rates of non-participation in physical activity than White children (CDC, 2017). Please see Figure 1 B for a graphical representation.

Fig. 1B

\section{Percentage of High School Students Who Did Not Participate in at Least 60 Minutes of Physical Activity on at Least 1 Day, ${ }^{*}$ by Sex, ${ }^{\dagger}$ Grade, ${ }^{\dagger}$ and Race/Ethnicity, ${ }^{\dagger} 2017$}

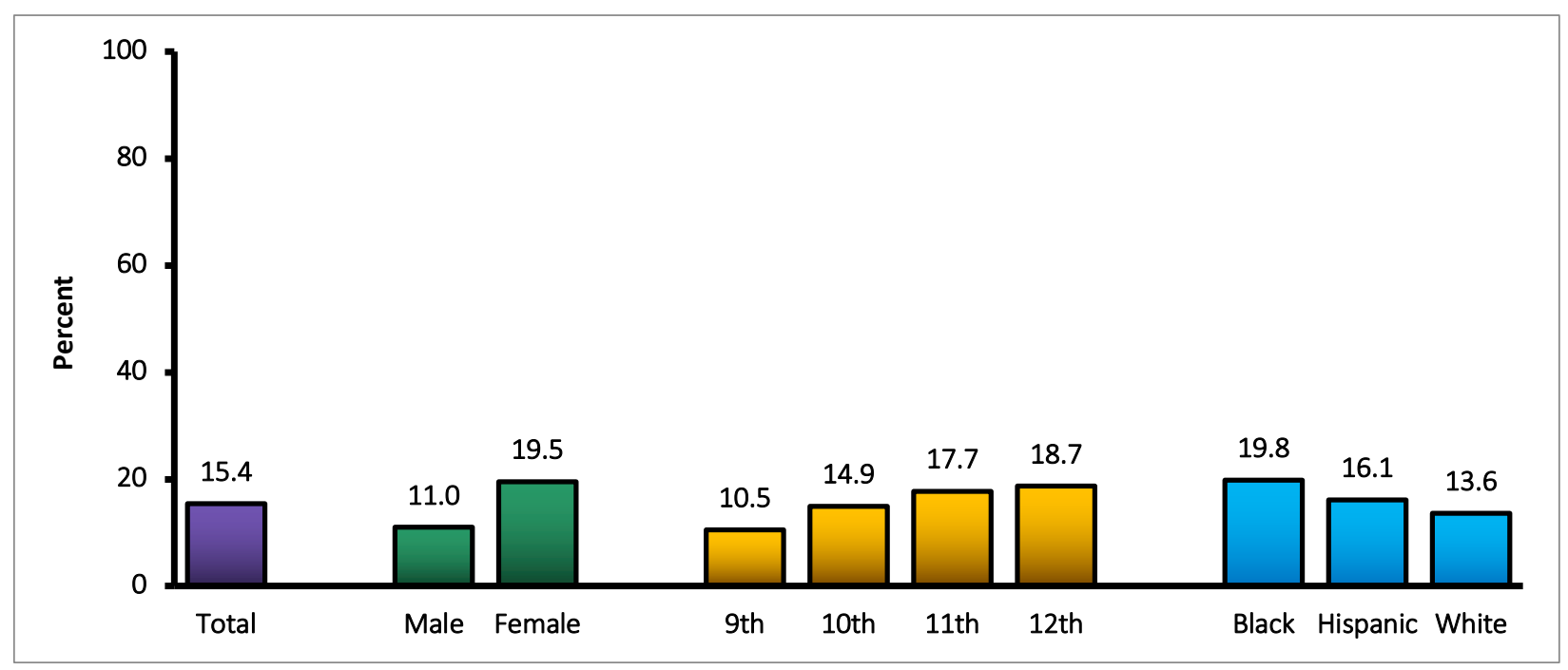

In any kind of physical activity that increased their heart rate and made them breathe hard some of the time during the 7 days before the survey

${ }^{\dagger} \mathrm{F}>\mathrm{M} ; 10$ th $>9$ th, 11th $>9$ th, 12th $>9$ th, 12th $>10$ th; B $>$ W (Based on t-test analysis, $\mathrm{p}<0.05$. $)$

All Hispanic students are included in the Hispanic category. All other races are non-Hispanic. 
Note: This graph contains weighted results.

Results obtained from the National Youth Risk Behavior Survey, 2017 
Further data from the YRBSS survey showed nutritional disparities among lowincome families as well. On average, a higher proportion of low-income children did not have adequate fruit or vegetable servings in their daily diets (CDC, 2017).

Lack of healthy food access in lower socioeconomic areas is a burden for many families as a whole. Many large-scale food retail stores that offer healthier options are often placed out of urban areas, making it difficult for families to access. Many cities in America are known as "food deserts", which are high poverty areas with restricted access to healthy food options (Sage, McCracken, \& Sage, 2013). There has been promising research in the use of local farmer's markets in urban areas that offer fresh local nutritious food choices to individuals relatively low to consumers. Many vendors accept governmentally subsides such as WIC as forms of payment that assist lower-income families with access (Ball et al., 2017). Other public policy efforts have focused on offering incentives to large chain grocers to open stores in economically deprived areas in urban settings to increase food options availability (Lee \& Lim, 2008). There is significant evidence that demonstrates a relationship between pediatric obesity and socioeconomic disparities. In a study that took place with Massachusetts residents in in 2015, data was analyzed from a previous 2009 study that looked at surrounding school districts and the relationship between overweight and obese students and low family income rates. It showed the overweight and/or obese status in students was associated with lower income rates significantly (Rogers, R. et. al, 2015). The trend between pediatric obesity rates and lower socio-economic status is seen at a national level as well especially among some population groups which calls for intervention approaches that can be tailored to meet the needs of the population (Wang, 2011). 
There have been many programs that have been implemented to treat pediatric obesity with mixed success. Successful programs have included physical activity, nutritional, and behavioral counseling (Cohen, Gottlieb, \& Underwood, 2001; Strauss \& Knight, 1999). Research has shown a lack of successful programs targeted at children from disadvantaged backgrounds (Cui et al., 2015). One of the most considerable barriers to getting children to participate in obesity management programs is engaging caregivers (Cui et al., 2015). However, the family environment plays a fundamental role in childhood obesity. Genetics, health-related behaviors, diet behaviors, physical activity, and sedentary behavior are influenced by the family surroundings (Jang \& Whittemore, 2015). The environment in which the child resides is crucial to maintaining health. The parental perspective can have a significant influence on the development and management of childhood obesity (Ordway et al, 2011). The family construct is a building block within the microsystem of society that needs to be supported for long-term success in childhood obesity reduction and establishing positive health-related behaviors (Jang \& Whittemore, 2015). Engaging in prevention-focused, socio-ecological approaches that encompass child development, primary relationships, culture, and community is essential to successful treatment outcomes (Lee, 2011). In a home visiting parenting program that focused on child obesity, research focused on offering a socioecological approach with families that looked at the parental attachment, health, mental health, parenting, and life course outcomes in delivering care. The goal was to prevent difficulties before they began by enhancing the parent-child relationships and family support to lower rates of childhood obesity. The program significantly lowered the 
obesity rate among two-year-old children living in low-socioeconomic status communities (Ordway et al., 2018).

Cui et al. (2015) set out to research recruitment and retention in obesity prevention and treatment trials targeting minority and low-income children. In an extensive systematic review of clinical trials, twenty-five studies focused on specific efforts focused on recruitment and retention. The studies that showed higher retention rates used culturally appropriate intervention activities and staff. The activities and processes successful in increasing retention included developmentally appropriate goals, counseling, technical support, and regular follow-ups with clinicians, incentives, food, recipe books, and exercise equipment. Obesity interventions involving the whole family while allowing children to create bonds offer support in the longer term (Jones, AlKudairy, Melendez-Torres, \& Oyebode, 2019). One evidence-based program that engages communities and is associated with the improved parental understanding of childhood health behaviors is called Let's Go! 5,2,1,0. In 2006, the State of Maine collaborated with the United Way and convened six of the region's largest employers in southern Maine to launch Let's Go! (Maine Health Let's Go, 2020).

Rogers et al. (2013), described a program called, Let's Go! 5,2,1,0. The program model has two significant components: deploying a simple message, 5,2,1,0 across multiple community settings to remind families and children how to make healthy choices, and implementing changes to environments and policies that support the beneficial options. The mnemonic, 5,2,1,0, represents four recommendations for healthy eating and physical activity each day: eat five or more servings of fruits and vegetables, the limit of two hours of screen time, engage in one hour or more of physical activity, and 
limit sugary drinks. A five-year study of the community program Let's Go! 5,2,1,0 showed that parents reported positive reactions and greater awareness of healthier habits (Rogers et al., 2013).

The role of the nurse can be influential in public health initiatives that target childhood obesity intervention. The nurse has a unique understanding of the community's needs, including health disparities and the role of health-related policies (Roberts, 1984). Focusing on health promotion and disease prevention efforts in childhood can provide essential strategies for reducing chronic disease (Langford, 1997). A critical factor in optimizing health in childhood is building the capacities of parents and communities (Alicea-Planas, Sullivan, Tran, \& Cruz, 2018). A framework that describes the roles of policies and programs in building capacity and foundations of childhood health helps encompass children's basic needs and health foundations. Social, economic, and cultural determinants of health that include poverty and education can affect health (Mistry et al., 2012).

Additionally, places where children and families live, work, and develop, are ideal intervention sites. Using an ecological model built on the work of Bronfenbrenner (Harkonen, 2001) policymakers and practitioners focus on three steps: selecting programs and policies that enhance health, connecting capacities to foundations of health, and understanding how biological mechanisms link foundations and health outcomes (Mistry et al., 2012). The described framework outlined by Mistry et al. (2012) helps inform stakeholders in a community about policies and programs that can increase community capacities to improve childhood health. The nurse can be an influential stakeholder and help close a gap between understanding health policy in a community. 


\section{Organizational Assessment/Local Problem}

Nationally, there continues to be an upward trend in childhood obesity. Data from a 2015-2016 survey in the United States showed the prevalence of obesity to be $19 \%$ in children ages 2 years to 19 years (Hales et al., 2017). In 2019, about $10.5 \%$ of households in America were identified as food insecure, with higher insecurity rates in single-family homes and lower-income homes. Approximately $13.6 \%$ of families with children were affected by food insecurity in 2019 (USDA, 2020). Data from the national Kids Count survey showed that $26 \%$ of children aged $10-17$ years were considered overweight and obese in the state of Connecticut between 2017-2018. About 10\% of Connecticut's total population lives in poverty, as defined by the national poverty levels (Kids Count Data Center, 2020). Participation in the Supplemental Food Assistance Program (SNAP) in Connecticut was under $10 \%$ of the population compared to national rates of participation averaging over 10\% (USDA, 2020). However, access to SNAP can have some challenges among families.

SNAP is a federally funded program and includes block funding for states to utilize. The block funding is a fixed amount and does not respond to increased needs such as economic downturn times. Adequacy of SNAP benefits can be too low related to geographic variation in food prices, cost variation with age and nutrient requirements for household members, and food preparation costs. Additionally, individuals receiving SNAP benefits must comply with general work requirements or face disqualification, meaning they have to be actively looking for employment (Oliveria, V, Prell, M., Tiehen, L., \& Smallwood, D., 2018) 
Since the beginning of 2020, the United States has experienced a widespread economic recession due to the COVID 19 pandemic. Before the COVID 19 pandemic, the United States saw rates of food insecurity rates that were steadily improving, but since the pandemic has begun, unemployment rates have risen (Feeding America, 2020). Projections for the year 2020 on food insecurity estimate that 54.3 million individuals will be food insecure, which is a stark increase from previous years (Center for Budget and Policy Priorities, 2020). Locally, it is projected that Connecticut will see a $16-17 \%$ increase in food insecurity rates in 2020 (Feeding America, 2020). The impact of COVID 19 on vulnerable populations related to food insecurity is severe. Unemployment rates for families with children have steadily increased in 2020 due to the COVID 19 crisis. So has food insecurity and the ability to purchase foods to sustain a healthier living. The impact on SNAP benefits from COVID 19 has been detrimental to those who need assistance the most (Center for Budget and Policy Priorities, 2020). The Families First Coronavirus Response Act passed in March 2020 included temporary provisions for SNAP to allow families to take the maximum amount of allotments (Center for Budget and Policy Priorities, 2020). However, families that previously were already accepting maximum allotments of SNAP benefits were excluded from taking more under the act. This leaves approximately $40 \%$ of households receiving SNAP excluded from obtaining higher funds under the act (Haider, 2020). Demand for charitable food assistance has increased and is expected to continue for the near future (Feeding America, 2020).

The U.S. Census report of 2010 indicates approximately 18,545 individuals are residing in Stonington, CT. Persons under the age of 18 comprise about $17.4 \%$ of the population. About $8.7 \%$ of the population is estimated to be living in poverty (United 
States Census Bureau, 2010). The Stonington Human Services Department's mission is to enhance the quality of life for Stonington residents by advocating for basic needs and promoting self-sufficiency (Stonington, CT, 2020). Programs that have previously been offered have stopped due to the COVID 19 pandemic. One of the most significant programs that lower-income residents received in Stonington was the mobile food pantry that United Way provided. Before the COVID 19 pandemic, the mobile food pantry would come monthly to Stonington to offer eligible residents food. Due to social distancing guidelines and limited funding during the pandemic, the food pantry truck have not delivered to Stonington in months (K. King, personal communication, October 2020).

The COVID 19 pandemic has forced many schools in the nation to adopt a hybrid or full-distance model. Students in secondary schools learn in a remote learning environment at home, often with working parents and limited resources. The State of Connecticut increased funding through the Department of Social Services (DSS) to \$34 million to provide additional SNAP benefits to families (CT.gov. 2020). School districts, including Stonington, offered meals to students attending remotely. However, barriers included transportation needs to obtain the food and limited staff and hours available to provide the food (B. Fowler, personal communication, October 2020).

\section{Purpose Statement and Specific Aims}

The purpose of the project was the utilization and evaluation of the resource nurse role in the improvement of healthy living behaviors by using an evidence-based intervention and connecting families with resources in the community to help sustain outcomes and reduce the risk of childhood obesity. Traditionally, when one thinks of a 
resource nurse's role, it is defined by providing mentorship to individuals. Using a resource nurse's role in a public health setting was exploratory. The purpose of the project was to evaluate the role of a resource nurse that worked with families identified as needing healthy living supports to reduce the risk of childhood obesity in a community. The quality improvement project utilized the resource nurse's role to reduce food insecurities associated with childhood obesity by using an evidence-based intervention to provide education and resources that improve outcomes by sustaining healthier living practices.

\section{Conceptual/Theoretical Framework}

The theory of social support is a middle-range nursing theory that addresses structure and interaction in relationships. It influences health status, health behavior, and the use of health services. A nurse can utilize the theory with clients and their families by promoting and strengthening social supports. Literature encourages the use of social supports that include health-promoting behaviors, personal competence, coping, a sense of well-being, self-worth, and decreased anxiety and depression (Langford et al., 1997).

The social support theory's four theoretical constructs include emotional, informational, instrumental, and appraisal supports. Emotional support involves the experience of being liked, admired, and respected. Informational support refers to providing information during a time of stress. Instrumental support is the provision of aid, goods, or services. Appraisal support affirms one's actions or statements (Barrera, 1986; Fleury et al., 2009; House, 1981; Tilden \& Weinert, 1987).

Professionals can intervene to strengthen social support networks for clients or choose to provide social support when lacking by helping individuals access resources in 
the community (Peterson \& Bredow, 2013). Cohen et al. (2001) described a stressbuffering model describing how social support contributes to health-promoting behaviors in persons experiencing stress. Individuals experiencing stress when provided with supports tend to make more health-promoting decisions that improve quality of life rather than decrease it. Providing support resources assist the individual with positive coping mechanisms in a stressful situation.

Nurses know to assess the interpersonal and social environments of clients and to implement health-promoting strategies. Using the social support theory's underpinnings, nurses can provide a network to determine social supports, use social networks, define professional and non-professional providers' roles to move individuals to increase independence, and evaluate community resources (Roberts, 1984).

The role of resource nurse utilized the social support theory by the clinical application of providing supports to a community of families. The interaction within the community organizations, the nurse, and the families could reduce food insecurity and increase health-promoting behaviors. The relationship of the nurse with the families and community provided a connection that fostered positive change and outcomes that can be sustained over time.

\section{Methods}

\section{Setting}

The quality improvement project took place in conjunction with the Stonington Human Services department in Stonington, CT. Stonington, CT is a costal seaside town in the county of New London on the border of Rhode Island. Stonington is comprised of the borough of Stonington, villages of Pawcatuck, Lords Point, Wequetequock, Mystic, 
and Old Mystic. Stonington historically is known as a fisherman's town with a large proportion of Portuguese and Italian residents. More recently, Stonington has seen an influx of residents from out of state looking to buy second homes in the area. Currently, the population of Stonington, CT is 18,545 individuals and about 8,210 households. It is estimated that $17.1 \%$ of population is aged 18 or younger, $92.5 \%$ of the population identifies as White, and $8.7 \%$ of the population is living in poverty as of 2019 (US Census Bureau, 2019).

\section{Participants}

The resource nurse worked with the social worker at the Department of Human Services (SHS) in Stonington, CT, to identify families that needed healthy living support. Please refer to Appendix A for permission for the resource nurse to work with SHS. The resource nurse described the evidence-based intervention to the social worker, and through convenience sampling families were identified that were receiving services within the department. The criteria used to identify families included families living at or below the poverty line and have been receiving supplemental food assistance from SHS. Additionally, they needed to have at least one child under 18 years living in the household. The initial sample included three single-family households with children that ranged from age 5 years to 16 years. The resource nurse obtained consent for the project (Appendix B) after initial identification of interest in the program for the three families. After the initial consent, one family withdrew for fear of being labeled as being poor. Upon further discussion with the social worker at SHS, it was revealed that trust is factor with many of the families that she works with and that could prevent some families from enrolling for fear of lack of trust (K. King, personal communication, 2020). 
Discussion ensued with the social worker about increasing the number of participants in the program. The resource nurse decided to reach out to the nurses and social workers at the local public schools. In October of 2020, the resource nurse reached out to the elementary, middle, and high schools' local school principles. The resource nurse described the program to the school nurses and social workers, and obtained a list of ten families. Out of the ten families identified and interested in the program, six of the families agreed to consent to the program. The lack of consent and participation in the four families' program was related to the lack of follow-up and time required to be in the program. A final sample of eight families consented and enrolled in the program. Please refer to Table 1 for final participant demographics in the program. 
Table 1

Family Demographics

\begin{tabular}{|c|c|c|}
\hline & $\mathrm{n}$ & $\%$ \\
\hline \multicolumn{3}{|c|}{ Number of Adults } \\
\hline 1 & 3 & $37.5 \%$ \\
\hline 2 & 3 & $37.5 \%$ \\
\hline 3 & 2 & $25 \%$ \\
\hline \multicolumn{3}{|l|}{ Marital Status } \\
\hline Single & 6 & $75 \%$ \\
\hline Married & 2 & $25 \%$ \\
\hline \multicolumn{3}{|l|}{ Children/Family } \\
\hline 1 & 3 & $37.5 \%$ \\
\hline 2 & 3 & $37.5 \%$ \\
\hline 3 & 1 & $12.5 \%$ \\
\hline$>3$ & 1 & $12.5 \%$ \\
\hline \multicolumn{3}{|l|}{ Ages } \\
\hline $0-5$ & 2 & $11.76 \%$ \\
\hline $5-10$ & 5 & $29.4 \%$ \\
\hline $10-15$ & 9 & $52.94 \%$ \\
\hline$>15$ & 1 & $5.88 \%$ \\
\hline
\end{tabular}

\section{Intervention}

An evidence-based educational program using the model Let's Go! 5,2,1,0 was implemented to address the educational need surrounding healthy living within families. To aid in food security assistance, a local community partnership with the Yellow Farm House in Stonington, CT, will be providing food assistance to the families weekly during the program. The weekly food deliveries consisted of fresh produce, including protein sources and recipe cards. The resource nurse delivered the food weekly during the program. The resource nurse sent a letter to all families enrolled describing the program (Appendix C). The letter included a telephone number and an email address for families interested in the program. Interested families were asked to make a telephone appointment with the resource nurse. At the initial telephone interview, the resource 
nurse obtained consent for the program and completed an intake sheet (Appendix D).

Following consent, the resource nurse administered the USDA food security

questionnaire to assess food security in the household. The USDA food security

questionnaire is available online for public use (USDA, 2020). Additionally, at the initial

intake call, all participants were given information on following the Let's Go! 5,2,1,0

program (Appendix E) and given a weekly sheet to track the program's progress

(Appendix F).

The timeline of the program was twelve weeks. The resource nurse set a time to deliver the food weekly to the families and conducted a telephone call with the families weekly to review the program's progress. Due to COVID-19 restrictions, communication was done via telephone and email with the participants. Delivery of food was made to the doorstep of the family's home at pre-determined times. If the resource nurse could not reach the families during the week, a message was left for the families to return the call, and a follow-up email was given.

After the program, the resource nurse administered the USDA food security questionnaire to compare pre-and post-program results. Additionally, the resource nurse asked the families to write a letter addressing the program's impact on them. If the resource nurse couldn't t obtain a letter regarding the program impact, one follow-up phone call and email was sent to the family.

\section{Measures}

The educational part of the program consisted of implementing the Let's Go! 5,2,1,0 rules. The Let's Go! 5, 2, 1, 0 rule was first implemented by the Maine Youth Overweight Collaborative obesity prevention program and implemented nationally in 
health campaigns since 2009. The intervention consists of the following consuming at least five servings of fruits and vegetables daily, limiting screen time to no more than two hours per day, attaining at least one hour of physical activity daily, and consuming zero sugar-sweetened beverages (Maine Health Let's Go Children's Program, 2020). Program materials from the Let's Go! 5, 2,1,0 program are available for public use. It has been widely used and studied as an evidence-based tool nationally and validated for use (Maine Health Let's Go National Program, 2020).

The U.S. Household Food Security Survey developed by the USDA Economic Research Service wasused to assess food security in the household. The survey consists of eighteen questions used to determine food security and insecurity. The survey is a three-part series and is ordered to assess adult and child food security. In conjunction with the Committee of National Statistics, the USDA helped define the terms used in regard to food security within the survey. The four ranges used are high food security, marginal food security, low food security, and very low food security. Placement on this continuum is determined by the household's responses to a series of questions about behaviors and experiences associated with difficulty meeting food needs. The questions cover a wide range of food insecurity severity (See Appendix E for survey questions). Statistical analysis used to validate the tool was based on the national food security survey conducted by the Current Population Survey (CPS). The CPS is a national survey conducted by the Bureau of the Census for the Bureau of Labor Statistics, including unemployment statistics, annual income, and poverty statistics. Each year after completing the labor force interview, about 40,000 households respond to the food security questions. The CPS interviews the households are selected to represent civilian 
households at state and national levels (USDA, 2020). USDA Household Food Security Survey is public and available for use without formal permission.

Throughout the program, the resource nurse spent time with each family reviewing their weekly successes and challenges with the Let's Go! 5,2,1,0 intervention and learning how to utilize healthier foods in their families. The phenomenon of interest in this part of the review was to capture an understanding of the families' perspective as it relates to the impact of the resource nurse intervention throughout the program by using an exploratory-descriptive qualitative method. As mentioned earlier, the theory of social support addresses structure and interaction within relationships. In theory, professionals have used the theory of social support to strengthen existing support networks for clients or choose to provide social support where it has been lacking by helping individuals and families access resources in the community (Peterson \& Bredow, 2013). In addition to using the framework of the social support theory, the resource nurse wanted to identify what specific supports were most beneficial and what resources families most utilized during the program.

Throughout the duration of the program, the resource nurse utilized semi structured interviews with the participants. Each week, the resource nurse spoke by telephone conversation to a family member participant. Using the weekly survey questions from Appendix F, the participants answered the questions in an open-ended style. The phone interviews used semi-structured interviews reviewing the Let's Go! $5,2,1,0$ plan and discussion about what was working for each family and what could go better. This allowed the resource nurse to gather rich qualitative data in real time during the twelve-week program. Note taking or memoing was the method used by the resource 
nurse to summarize conversations by telephone. Data from the note taking was coded using descriptive coding to help classify the elements of the data from the interviews that were similar. The resource nurse used unique codes as identifiers to protect the family identity. Throughout the twelve weeks, the resource nurse continually reviewed notes and conversations with participants to assist with the identification of patterns that were common to the families' experiences within the program. The resource nurse highlighted keywords within the notes and memos that were similar. The resource nurse and the project advisor reviewed the data to reach consensus on emerging themes. Thematic analysis helped identify three emerging themes in the data that shared commonalities (Gray, Grove, \& Sutherland, 2017). Three themes emerged throughout the program and are collectively labeled as follows, connections, support, and education. Each theme is explored in the results section.

\section{Analysis}

The resource nurse used a mixed method design to analyze the results of the program. Descriptive statistics were used to analyze nurse hours spent with participants and community partners. Comparative analysis was used to analyze food security rates pre and post program on participants. A Fisher's Exact Test was utilized to test significance of the program on food security rates in households of the participants in the program. The web-based program Med Calc (Schoonjans, 2021) and Graph Pad (GraphPad, 2021) was used to complete the Fisher's Exact Test. Quantitative data and statistical data was verified by a statistician. Qualitative data was reviewed using note taking on participant experiences to analyze data saturation to identify themes. 


\section{Ethical Considerations}

Participants were made aware of the risks related to the study during the informed consent at enrollment. Risks were minimal and not more than they would encounter in their daily lives. The families were identified as already having difficulty obtaining food resources needed to sustain a healthier living and need assistance. The purpose of the program was to evaluate the role of the nurse in educating and assisting families with resources needed to sustain healthier living practices. Identities were concealed to protect the participants. A list of contacts was given on the consent forms for any issues encountered during the program. A full list of disclosure is available on the consent form (Appendix B).

Rhode Island College (RIC) IRB consent was obtained in October 2020 as a quality improvement project. Informed consent was obtained from all participants at the beginning of the study (See Appendix B). Participant's names were coded numerically and data was stored in a password-protected computer. A \$25 Wal-Mart card was given as a stipend incentive to each family at the completion of program.

\section{Results}

Over the course of the program of twelve weeks, the resource nurse logged 182 hours with families and community contacts, with an average of about 23 hours per family. At the initial start of the program, it was determined that the program would last twelve weeks. The following table (Table 2) summarizes the number of contacts made with the families and resource hours spent over the course of the program.

\section{Table 2}

Number of Contacts and Contact Hours per Family 


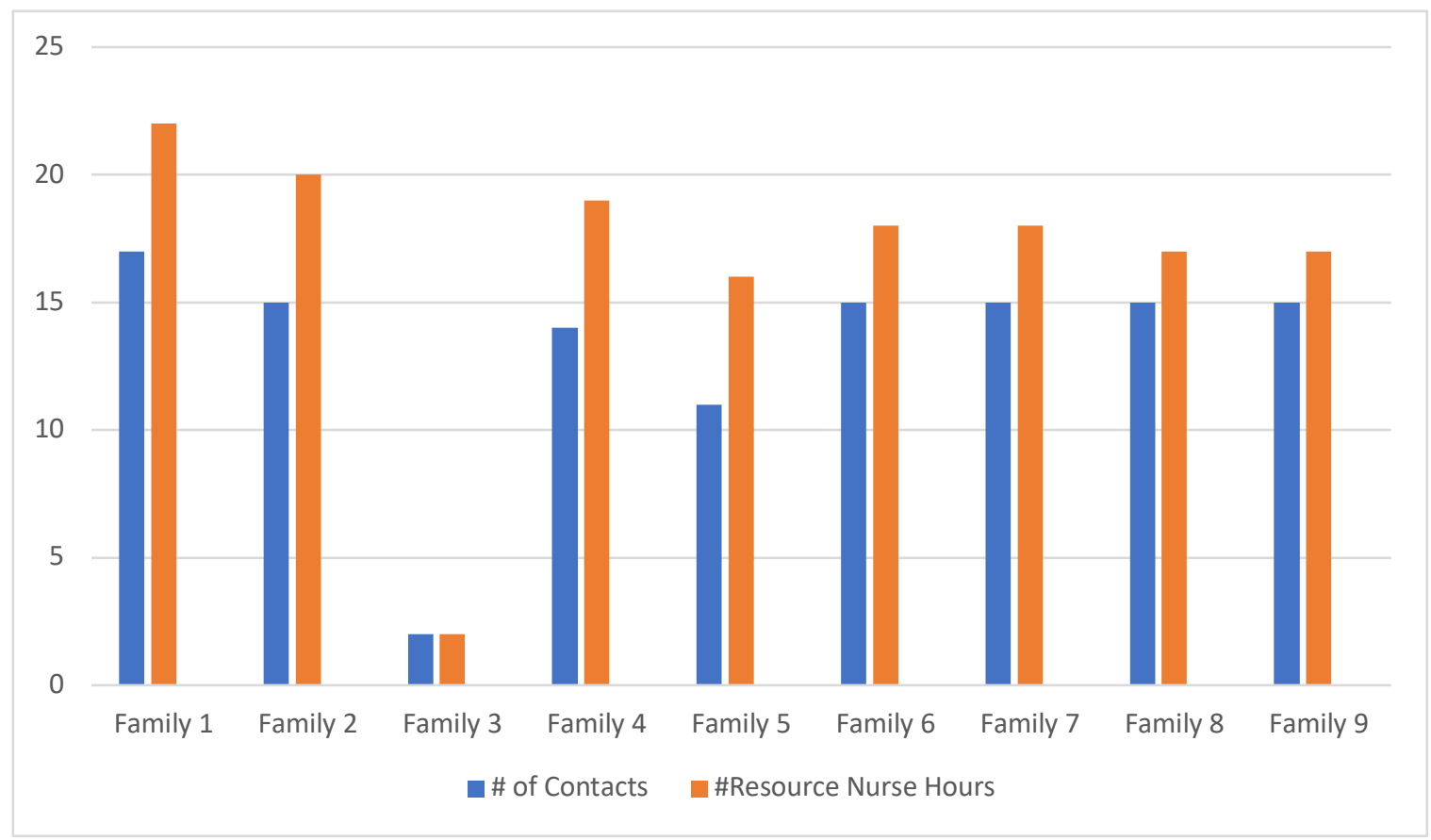

The resource nurse spent time collaborating with community partners throughout the program as well. The timeline of the program fell during the holiday time of 2020 and during the COVID 19 pandemic. Additional resources that were identified as needed were holiday meals and supplies needed for cooking assistance. The community partners included the Yellow Farm House, the social worker at Stonington Human Services, the nutritionist for the Stonington Public School System, community members during the holiday time to coordinate hot meal deliveries and supplies for families in need. A summary of hours spent by the resource nurse and community partners is displayed in Table 3 .

\section{Table 3}

Community Partner Contacts and Resource Hours 


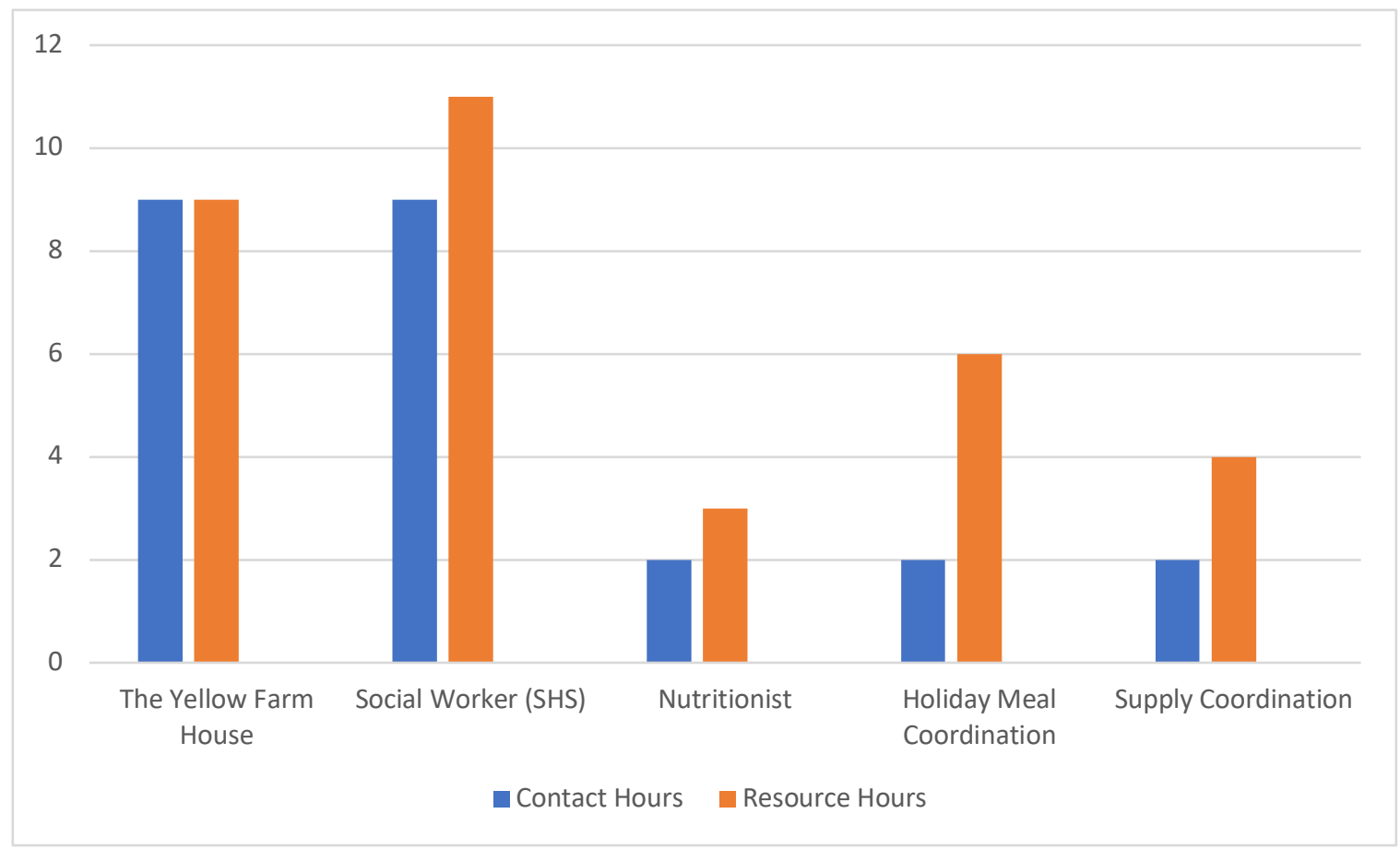

The families were given a weekly sheet to fill out that included a questionnaire with a Likert rating scale that allowed them to rate their participation level with the Let's Go! 5,2,1,0 program, see Appendix G for the tool used. The guidelines were that they ate five fruits and vegetables a day, had two hours or fewer of media time a day, one hour of physical activity a day, and zero sugary beverages. The resource nurse encouraged them to work together on the program's goals together as a family to increase all members' participation. They were to rate themselves on a scale from $0-10$ weekly, with zero being no participation with the program at all, and level 10 being that all family members followed all parts of the program. The resource nurse collected the data over twelve weeks of the program. The data is summarized visually in Table 4. Most families averaged a score of seven out ten on the Likert scale. There were some dips of participation in the Let's Go! 5,2,1,0 program in the midpoint of the program due to holiday week and two of families had contracted COVID-19 and were unable to participate fully for two weeks. A few weeks of data from some of the families was 
missing due to lack of follow up with return phone calls that week. Overall, most of the families found the guidelines of Let's Go! 5,2,1,0 to be easy to follow and a great way to live healthier. One client mentioned to the resource nurse that by week eight he had lost six pounds of weight and his total triglyceride levels had dropped by following the program.

\section{Table 4}

Average Weekly Participation in 5,2,1,0

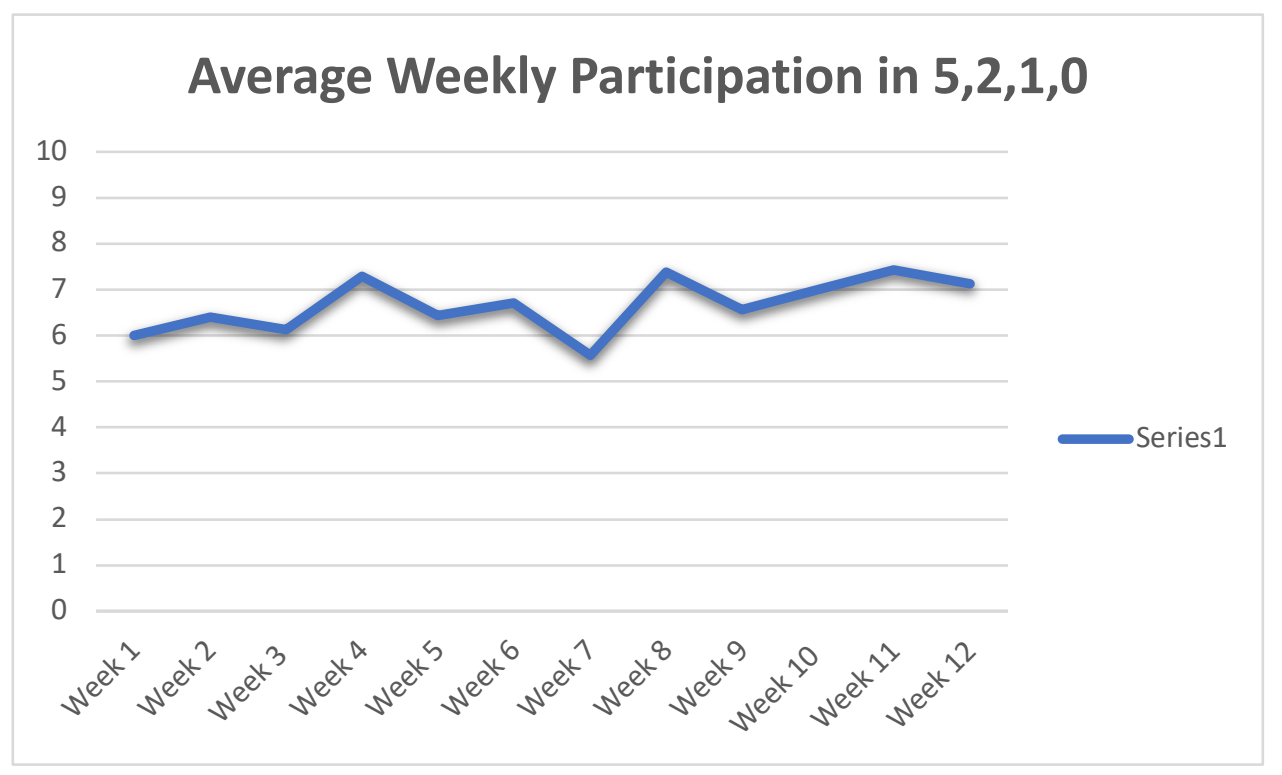

An essential part of the program was identifying needed daily living resources by the families to the nurse. During the weekly conversations with the families, many discussions ensued regarding numerous referral connections to make the program outcomes successful.

Many requests were similar between families and prompted the resource nurse to send weekly emails to the families enrolled in the program. The email themes would vary from week to week and focused on a topic associated with improving healthier habits. One common theme among the children in the program was the increased screen 
time related to home-based remote school learning and media. To address this, an email was sent to the families on tips to teach the children ways to increase physical activity during breaks from school and limit non-school-related media by trying different activities away from the screen. Other requests included recipe ideas to utilize the products delivered from the Yellow Farm House. The resource nurse would send out recipe ideas and information regarding the foods delivered weekly to the families. Additionally, the Yellow Farm House invited the families to partake in weekly virtual cooking lessons for free that would focus on cooking the week's produce. Some of the families could not participate in the cooking lessons by the Yellow Farm House related to scheduling difficulties but were provided with YouTube links on accessing related cooking lessons virtually.

During the holiday, many families that were enrolled in the program noted difficulty obtaining funds to afford a holiday meal or the inability to be with family related to COVID 19. The resource nurse was able to connect families with local community members that we're able to provide holiday meals for free. The resource nurse collaborated with each family and community member to conceal identities and delivered the meals to the families that requested them. Four family holiday meals were arranged for the families enrolled.

As the program, progressed, other families reported needing assistance with heating their homes and how to apply for benefits such as the Supplemental Food Assistance Program (SNAP). The resource nurse connected the families with the social worker at the SHS that assisted them with these services. In addition, one family member 
reported to the nurse that she needed counseling services. The resource nurse was able to use the connection with SHS to assist with getting the services provided.

The graph in table 5 illustrates the number of referrals made by the resource nurse to community partners.

Table 5

Referrals to Community Resources

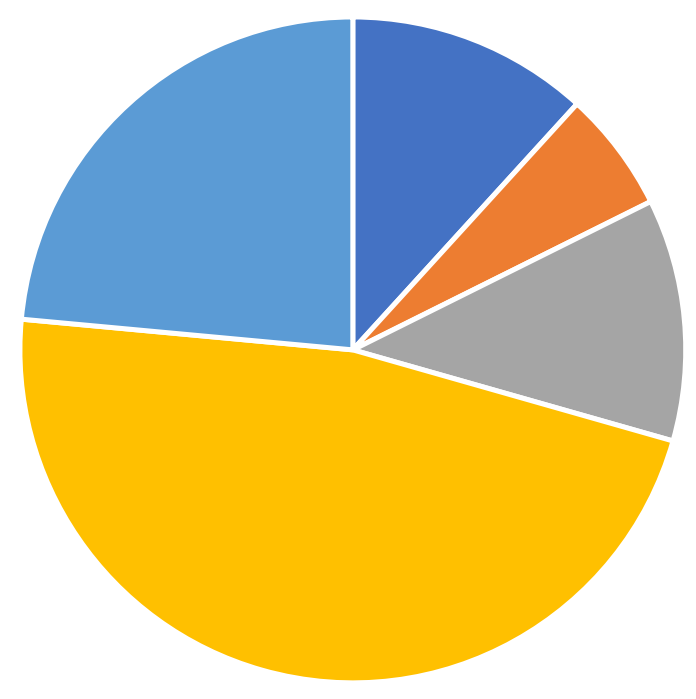

- Heating Assistance

- The Yellow Farm House
- Nutritionist - Holiday Meals

One of the most meaningful community referrals was to the Yellow Farm House Educational Center's connection. Families were encouraged and found it beneficial to connect to a farm that provided the ability to have locally grown food. The families mentioned that the children became active in learning how to cook the food received and gained knowledge from the material of the Let's Go! 5,2,1,0 program and the weekly emails the resource nurse sent out. One parent's comment stated, "My son likes to eat salad now," and another parent saying, "My daughter asks me for parsnip fries now". 
Another parent said, "My five children enjoy cooking on Saturday mornings in the kitchen pretending that they are on a cooking show."

Another measure the resource nurse took during the program was the food security pre/post program rating. The USDA definition of food insecurity is defined on two conditions. One is low food security, which is defined as reports of reduced quality or variety of the diet and little to no diet change. Second, very low food insecurity is defined as multiple reports of disrupted eating patterns and reduced food intake. The USDA defines food security based on two categories. One being high food security, meaning no reports of indications of food access or limitations. Second, marginal food security reports that there are one or two indications of food insufficiency or food shortage in the house but no dietary intake changes (USDA, 2020). Raw scores were computed and interpreted based on the USDA definition of food security and insecurity. According to the survey module for families with one or more children, the raw scores are interpreted as follows:

Score 0: High food security

Score 1-3: Marginal food security

Score 3-5: Low food security

Score 6-18: Very low food security

The resource nurse administrated the USDA Food Security Questionnaire at each family's intake appointment over the phone and during the last week of the program. Individual family results are summarized in Table 6 below. 


\section{Table 6}

Food Security Rating Pre/Post Program

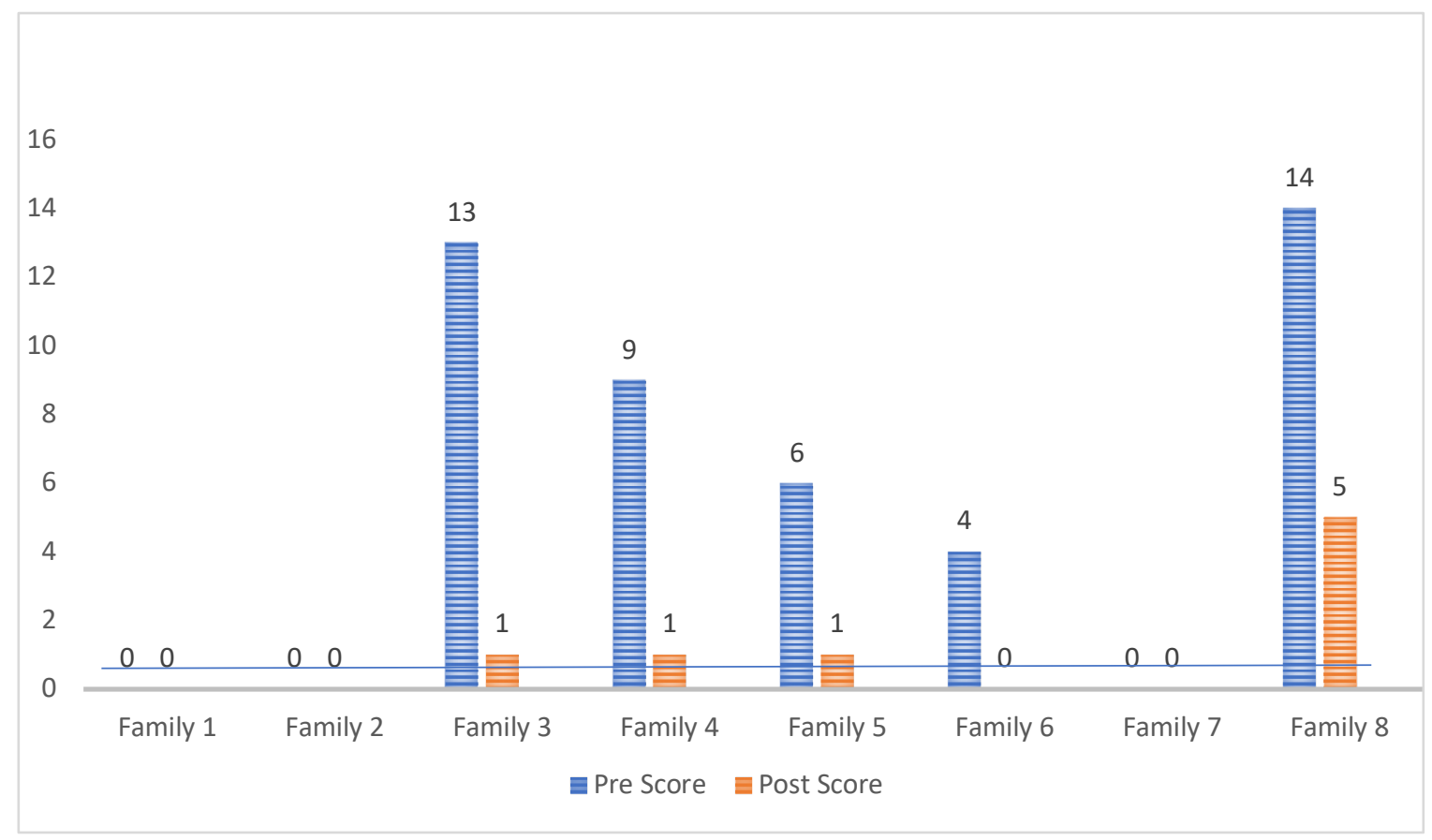

\begin{tabular}{lll}
\hline & \multicolumn{2}{c}{$\begin{array}{c}\text { Food Insecurity Rating } \\
\text { All Families }\end{array}$} \\
\hline Pre-Intervention & Post Intervention & P-value \\
$5.75(0-14,5.40)$ & $1(0-5,1.58)$ & 0.59 \\
\hline & Food Insecurity Rating \\
& Families with Baseline Food Insecurity Only \\
\hline Pre-Intervention & Post Intervention & P-value \\
$9.2(4-14,3.87)$ & $1.6(0-5,1.74)$ & $0.02^{*}$ \\
& & \\
\hline
\end{tabular}

pre- and post-intervention values reported as mean (range, SD), Differences in pre- and postintervention scores determined using a one-tailed Fisher's Exact test.

* indicates statistical significance.

According to the USDA food insecurity survey, out of the eight families, five families had reported some degree of food insecurity at the beginning of the program. 
Most of the collected and reviewed responses regarding food insecurity indicated that the adults in the household often felt that they did not have enough money to last the month for food. Other food insecurity results included that the adults in the house would go hungry before letting their children become hungry. The adults would often rely on lowcost foods to feed their families to stretch their budget to last for the month.

Post-survey results showed a significant improvement in the five families that reported some degree of food insecurity in their households. Family eight still reported having low food security from having very low food security at the end of the program. Upon further investigation, the family was currently waiting to hear about getting SNAP benefits and had not heard of the decisions by the end of the program. Of the families that rated themselves as food insecure prior to the program $(n=5)$, four families stated that having access to healthy food each week was a critical factor in improving their food security ratings in the program.

\section{Connections}

Throughout the program, participants frequently would request information on local programs and agencies that could provide additional resources for their households. Most requests were related to social services, such as gaining knowledge regarding how to apply for energy assistance or supplemental food assistance. It became clear to the resource nurse that those healthy living changes would not be achievable for most families without necessities in place within a household. Many families shared that they did not have the knowledge or confidence to reach out to the social service agencies on their own related to lack of knowledge on how to do so. 
One family had recently lost their job due to the COVID 19 pandemic and was unaware that funds were available in the community related explicitly to unemployment and COVID-19. The resource nurse was able to connect the family with a social service agency to assist with applying funds for their family. Additionally, this family had suffered personal loss during the program and needing a helping hand to guide them to assistance. The experience this family had with the program is best summed up in the following quote, "The resource nurse helped us connect with programs related to mental health, energy assistance and additional food resources that helped us not only during the program but after its conclusion as well."

Another family did not have proper cooking utensils in her home to prepare the produce that were being delivered weekly. She mentioned that she would often throw it away when she received food due to not having the equipment available to cook it. This family identified themselves as being very low food secure, and the mother would often go hungry during the month for lack of funds to get food. The resource nurse reached out to the local community agencies and was able to find a community member donating cooking utensils and supplies. This connection allowed the needed supply of cookware for this family. After the delivery of the cookware, the mother of the family started to use it and increased her participation score with the program. The following quotes sum up the family's experience with the program, "I found your program while my family was in dire need of food after a move from out of state," "your contributions brought challenges to us to try new things and new ways," and "it brought laughter, curiosity, and teamwork into the kitchen!”. 
One family member had recently started her own Etsy shop selling handmade recyclable items. The woman mentioned to the resource nurse that selling her things had been increasingly difficult during the COVID 19 pandemic. Through the Yellow Farm House and Stone Acres Farm connection, the resource nurse connected the woman to the farm. The farm has a daily farm pantry stand that sells locally made items. The woman set up a contract with the farm to sell her things and provide an additional income for her family. Her quote is as follows, "Thank you to the resource nurse who assisted me in making this connection, "as a struggling small business owner, this connection helped grow my business locally and is meaningful."

Besides having meaningful connections to the families enrolled in the program, the resource nurse connected with local agencies. The Yellow Farm House coordinators were essential partners throughout the program. The partnership allowed the delivery of weekly produce to the families and the ability for the families to access educational material through the virtual learning classes they offered. The classes at the Yellow Farm House centered on healthy eating and cooking, particularly with locally grown produce. The partnership has the potential of helping the community, and the partners at the Yellow Farm House were eager to see the results of the program the resource nurse was conducting. They previously had applied for grants to allow scholarships to families and participants that could not afford programs. They reported feeling that the results from the program can assist in their grant funding towards the initiative as supported by the following quote, "having strong testimonials from the people that received the food this winter helps our funders connect with the actual people who are receiving the benefits" (L. Jackson, personal communication, May 6, 2021). 
The social worker at SHS expressed her praise to the resource nurse for being an instrumental force in the community by connecting families to services that had not been connected before. Her quote, "Without your presence, these families would not have had the means to reach out to our agency for services." The resource nurse role helped fill a gap in SHS services during the COVID 19 pandemic related to the lack of offered programs. As the social worker stated, "having a nurse in the community allowed connections that previously were not there.”

\section{Support}

The theme of support was evident throughout the program. The resource nurse provided support to the families in numerous ways. The following quotes assist with supporting the theme, “we are a family that doesn't look like there is a problem, but there are things that are skipped because of lack of money," "thank you to resource nurse for not judging our situation and providing us with information on resources regardless of what we looked like."

The trust built between the resource nurse and the families allowed more open dialogue during the weekly phone check-ins. Families more than once shared personal struggles that related to their lives and affected their participation in the program. One family shared how they were struggling with a COVID diagnosis and was afraid to mention it to the resource nurse for fear of not participating in the weekly food deliveries. The family also said that they could not work because of the COVID diagnosis and had to take a leave of absence without pay. The family reported this during the 2020 holiday season, causing a significant decrease in income. Through the collaboration with SHS, 
the resource nurse was able to obtain an application for COVID relief funds offered by the Town of Stonington to residents that COVID financially impacted.

In addition, throughout the program families asked for suggestions to help their families increase their participation with the Let's Go! 5,2,1,0 program. The families understood the principles that the program stood for but needed support to make it work for their families. Each week during the phone interviews the resource nurse would listen to the weekly challenges and successes and summarize what each family said. This prompted the resource nurse to mail weekly newsletters in a form of an email to the families. The weekly newsletters would highlight a particular topic, for example, getting children active in the kitchen or tips for engaging children in physical activity outside.

The following examples highlight the benefits that the program provided utilizing the support. One family stated that it was often hard to cook healthy meals at home because of work schedules and found it easier to grab fast food on the run. The resource nurse could decipher what foods they liked and offered suggestions for quick meal prep tips that would allow the family to choose healthier snacks on the go and avoid fast food runs. The family stated, "the program has given us tools that I need to make better choices when I am grocery shopping, and it has shown me how to make better choices to the foods that my daughter and I love to eat." Another family stated, "At the start of the program, we focused on cutting down on our children's screen time as the program suggested, doing so really brought our attention to how much time they were spending in front of technology, on top of all the demands of distance learning. Cutting down on this, plus challenging ourselves by adding and including daily exercise with our children, really helped us build a stronger connection to them, that quite frankly, I didn't realize 
needed to strengthen!". Some families mentioned that just having a professional cheer them on and support them in making positive changes was encouraging. They looked forward to weekly and made them accountable. One family stated, "Receiving the local, fresh, and healthy food each week and having the resource nurse smiling every time delivering the food gave me something to look forward to."

\section{Education}

The theme of education becomes an underlying concept of the program. The families expressed a desire to want to be healthier but lacked the knowledge of making the change work for their families. The resource nurse used the evidence-based program, Let's Go! 5,2,1,0 to guide them in making changes that were easy and attainable for all members of their families.

Throughout the program's implementation, the resource nurse would educate the families on different aspects of the 5,2,1,0 program. For example, the resource nurse taught about a vegetable or fruit serving and how kids can be encouraged to eat them. Other measures included different activities that did not involve using an electronic or helped engage family participation. The weekly deliveries of food brought an opportunity to educate the families on what the foods were and how to cook and utilize them in their diets. The resource nurse would often print a recipe of the week to include with the deliveries. Most families reported difficulty getting less than two hours of media time a day because of online schooling and being in the winter season. The resource nurse educated the families on wintertime activities outside and family-friendly projects that can be done together to engage active participation away from electronics. 
Some examples of how the resource nurse's provision of education affected families is summarized in the following sentences. "The resource nurse allowed us to see how far we can commit to something with proper knowledge." "My son has expanded his choices for healthy eating and puts in the effort to eat healthier, exercise, and limit his screen time; it is wonderful for us to see him working towards his goals." "My son eats salads now, thanks to the resource nurse; he even orders it as a side when we go out to eat, which is a welcome breakthrough." "My family has had the opportunity to cook with fresh local produce, and it has expanded our vegetable variety."

\section{Discussion}

The purpose of this study was to evaluate the effectiveness of a novel communitybased resource nurse role in implementing an evidence-based intervention among families with an identified need for health living support resources and achieving improved sustainable healthy lifestyles and reducing risk for childhood obesity. The resource nurse conducted a pilot project using an evidence-based intervention to introduce beneficial living changes to the families and sustaining these changes with proper connections, support, and education. The project results support the hypothesis that a community-based resource nurse who provides supports for families increases the sustainability of their compliance with healthier living practices. The results of this project provide supporting evidence that the nurse's role can be influential in providing support in the community in regard to health behaviors and change.

There are key findings of this research. First, the nurse's presence and support in an evidence-based program increased compliance with positive outcomes as it related to participation in the Let's Go! 5,2,1,0 program. Second, the connections made with 
community agencies such as the Yellow Farm House and SHS provided a network to the families in means of community support to sustain healthier living practices. There was a significant increase in food security made in participants that had identified themselves as food insecure prior to the program. Out of the five families that were food insecure at the start of the program, four of the families became food secure and one family improved their ratings of food security but still remained slightly food insecure due to the lack of SNAP benefits. That family had a pending application for SNAP benefits.

This pattern of results is comparable with the previous literature by Ordway et al. (2018) that highlighted the role of a social worker and pediatric nurse that provided weekly visits to pregnant women in their third trimester through the child's second birthday. Ordway et al. (2018) hypothesized that using prevention-focused socioecological approach home visiting programs might decrease childhood overweight and obesity in early life. Ordway et al. (2018) found that the program's comprehensive approach and primary prevention design likely contributed to increasing parental attachment, health, mental health, parenting, and life course outcomes. While this present program conducted by the resource nurse worked with families and older children, the comparisons with Ordway et al. (2018) show that using a nurse to engage caregivers in primary health measures and providing connections to community resources actively assists in increasing compliance of outcomes. Having a healthy therapeutic relationship enhances wholeness and healing, and it is key to health promotion. Having a therapeutic nursing presence demonstrates caring, empathy, and connection, qualities required to build rapport and trust between a nurse and a client (Boeck, 2014). More than one family mentioned to the resource nurse that initial hesitations regarding the program were related 
to the stigma of needing financial support and the admission of needing help. The resource nurse helped alleviate any hesitations on the families' participation as evidenced by the direct quotations that related to the nurse having an empathic presence that was non-judgmental and trusting.

The program's results are consistent with the claim that family life and health is connected (Jang \& Whittemore, 201). Using the childhood health promotion framework one can optimize childhood health and build capacities for caregivers and communities (Mistry et al., 2012). Focusing on primary prevention measures such as healthy living behaviors and resources to decrease food insecurity gives caregivers enhanced support to change a positive way to support healthy living. More importantly, the role of the nurse is significant in programs that focus on health promoting behaviors. Funding for a nurse in a community setting can be made at a policy level. Increasing programs similar to this one will positively impact families and provide a connection that is needed.

Past researchers have found that efforts to recruit and retain participants in clinical trials related to health, specifically obesity and low-income status, have been challenging (Cui et al., 2015). In this study, the researcher found that trust between the families and the nurse was a critical factor in retention. Cui et al. (2015) used incentives such as grocery cards and recipe books and noted that bonds between staff in their study and participants did show an increase in client engagement in their research. The resource nurse highlighted that building a therapeutic relationship with the families was key to success in their outcomes.

This program's results represent the first direct demonstration of using the resource nurse's role in a community setting with families that are struggling with health- 
promoting behaviors. Findings from this study highlight the nurse's position and the connections provided to families that promoted their overall success.

Study findings also support the resource nurse as being influential to the program's success. The most compelling explanation for this is the quotes from the family participants. It was clear to the resource nurse that the role provided a sense of connection and trust. The resource nurse demonstrated through the program that families that struggle with food insecurity tend to make choices related to health that can contribute to the rise and onset of obesity. Families enrolled in the program that reported a level of food insecurity admittedly reported relying on lower-cost high-saturated fatty foods to feed their children. However, families were able to be educated with the Let's Go! 5,2,1,0 program on changing health practices and community connections that increased their food security ratings and consumption of healthier foods. The program's findings indicate that having a nurse present in the community setting that facilitate programs related to health practices in families can be beneficial in increasing food security in identified low food insecure homes that has further had the potential for childhood obesity.

Although the present program results support the resource nurse's role in the community setting, several limitations were identified. The program participants were obtained by convenience sampling through connections between the social worker and school nurse. The participants were suggested because they had identified a need to the agencies in the past and because the school nurse and social worker thought they could benefit from the program. This could have led to bias related to personal preferences on the school nurse and social worker's part. Additionally, there was a low enrollment of 
families in the project, making it difficult to generalize findings to a broader audience. These limitations could be addressed in future research. For example, using the resource nurse's model role and an evidence-based intervention like the Let's Go! 5,2,1,0 program in different settings with more detailed recruitment approaches could help obtain a higher sample of participants.

Despite these limitations, the results of the program suggest several theoretical and practical implications. For example, the theory of social support is highlighted in this program. The resource nurse intervened to strengthen social support networks for families and provided social support by helping families' access resources in the community that strengthened social supports that improved health behaviors during the program's duration (Peterson \& Bredow, 2013). This program also highlighted the resource nurse's role in therapeutic client relationships with family members. Having a nurse skilled in therapeutic communication and relationship building helps foster trust and open communication lines and the identification of challenges that families may be facing.

\section{Sustainability and Scalability}

The program highlighted in this paper is a pilot project and grassroots initiative that took the idea of resource nurse and placed the role in a community to work with families that needed healthy living supports. Using research on childhood obesity and food insecurity, the resource nurse deducted that using primary health promotion measures and connections to community organizations would increase food security and healthy living behaviors in families. The Yellow Farm House provided funding for the 
delivery of produce through a grant. Additionally, Stonington Human Services provided funding for the gift cards that the families received after the program.

The program highlighted the resource nurse's value in the community and was supported by the positive reviews from community partners and families. The long-term sustainability of the program will rely on ongoing grant funding for program supplies and nurse hours. Presenting the program outcomes to community partners will increase the likelihood of obtaining future grants on lasting partnerships with the nurse. The resource nurse is planning to distribute the program findings in publications and at a national conference to share the work done to network with other professionals and agencies for the work's ongoing support.

At the program completion, the SHS director reached out to the resource nurse with an invitation to join the Stonington Prevention Council (SPC) for the town. The council's mission statement is to permanently change community attitudes, laws, and policies to stop substance abuse and establish a safer community. The director of SHS is hopeful with the addition of a nurse on the council that the sharing of healthcare expertise will expand the council's mission to include other initiatives such as healthy living practices in the community.

\section{Conclusion}

Childhood obesity is a national health epidemic in the United States today and research shows that children living in lower socioeconomic households are more at risk for developing obesity (CDC, 2019). Food insecurity rates are higher in lower socioeconomic groups and rates have risen to close to $10.5 \%$ of US families identifying 
themselves as food insecure in 2019 (USDA, 2020). The connections between food insecurity and childhood obesity are strongly correlated with one another. As a Doctor of Nursing Practice (DNP) leader, was able to use advanced skills to identify the connection between low food insecurity and childhood obesity through the use of evidenced based practice in population health. Identifying a need in the community and implementating the program highlighted the role of the DNP scholar in collaboration and population focused care. This program utilized the role of the resource nurse in a community and aimed to improve healthy living behaviors in participants and connections to healthy living resources. Additionally, the program aimed to demonstrate value to the resource nurse role in a community. The program results show the impact of the resource nurse on the families by providing a sense of connection, support, and education that allowed families to make healthier living choices that are sustainable through resources provided by the resource nurse. Additionally, the improved food security rates in families that were food insecure at the beginning of program $(n=5)$ was statistically significant showing a positive impact on interventions used by the resource nurse in the program. Implications for practice include the potential benefit of more wide-spread use of the resource nurse role in community settings to work with at-risk populations struggling with food insecurity and at risk for obesity to develop programs that can provide primary interventions to reduce at-risk potential. Future research suggestions include applying the concept of the project in a broader setting with more participants. However, the utilization of the resource nurse is a concept that can be broadly adapted and used in future research. As a DNP scholar, the nurse can use the position to advocate for community health through thoughtful public testimony for policy development and public 
planning groups that will promote primary prevention programs aimed at reducing at risk potential for pediatric obesity. 


\section{References}

Abbasisi, A., Juszczyk, D., Van Jaarsveld, C.H.M., \& Gulliford, M.C. (2017). Body mass index and incident type I $t$ and type II diabetes in children and young adults: A retrospective cohort study. Journal of Endocrine Society, 1(5), 524-537. https://doi.10.1210/js.2017-00044

Alicea-Planas, J., Sullivan, K., Tran, H. \& Cruz, A. (2018). Planting seeds to grow healthy children: Strategic community partnerships. Health Promotion Practice, 20(1), 78-84

Anderson, P. M., \& Butcher, K. F. (2006). Childhood obesity: trends and potential causes. The Future of Children, 16(1).

Ball, L., McCauley, A., Paul, T., Gruber, K., Haldeman, L., \& Dharod, J. (2017).

Evaluating the Implementation of a Farmers' Market Targeting WIC FMNP Participants. Health Promotion Practice, 19(6), 946-956.

https://doi.org/10.1177/1524839917743965

Barrera, M. Jr. (1986). Distinctions between social support concepts, measures, and models. American Journal of Community Psychology, 14(4), 413-445.

Boeck, P. (2014). Presence: A concept analysis. Sage Open. Doi:

$$
10.1177 / 2158244014527990
$$

Center for Budget and Policy Priorities. (2020). Tracking the COVID 19 recession's effect on food, housing, and employment hardships. 
https://www.cbpp.org/research/poverty-and-inequality/tracking-the-covid-19recessions-effects-on-food-housing-and

Centers for Disease Control. (2017). High School YRBS: Connecticut 2017 Results. Retrieved December 12, 2018, from https://nccd.cdc.gov/youthonline/app/Results.aspx?LID=CT

Centers for Disease Control. (2017, October 13). Products - Data Briefs - Number 288 October 2017. Retrieved from https://www.cdc.gov/nchs/products/databriefs/db288.htm.

Centers for Disease Control (CDC) (2019). Childhood obesity facts. https://www.cdc.gov/obesity/data/childhood.html

Cohen, S., Gottlieb, B.H., \& Underwood, L.G. (2001). Social relationships and health: Challenges for measurement and intervention. Advances in Mind-Body Medicine, $17,129-141$.

CT. gov (2020). Pandemic EBT. https://portal.ct.gov/DSS/SNAP/PandemicEBT\#: :text=The $\% 20$ Connecticut $\% 20$ Department $\% 20$ of $\% 20$ Social,emergency $\%$ 20Supplemental\%20Nutrition\%20Assistance\%20Program\%20(

Cui, Z., Seburg, E. M., Sherwood, N. E., Faith, M. S., \& Ward, D. S. (2015). Recruitment and retention in obesity prevention and treatment trials targeting minority or lowincome children: a review of the clinical trials registration database. Trials, 16(1). doi: 10.1186/s13063-015-1089-Z 
Feeding America. (2020). The impact of coronavirus on food insecurity. https://www.feedingamerica.org/

Fleury, J., Keller, C., \& Perez, A. (2009). Social support theoretical perspective. Geriatric Nursing. 30(2S), 11-14.

Gray, J.R., Grove, S.K, \& Sutherland, S. (2017). The Practice of Nursing Research ( $8^{\text {th }}$ ed.). Elsevier.

GraphPad. (2021). Analyze a 2x2 contingency table. GraphPad. https://www.graphpad.com/quickcalcs/contingency1/.

Haider, A. (2020, July 28). 12 million people have been excluded from emergency increases in SNAP benefits. Center for American Progress. https://www.americanprogress.org/issues/poverty/news/2020/07/28/488085/12million-people-excluded-emergency-increases-snap-benefits/

Harkonen, U. (2007). The Bronfenbrenner ecological systems theory of human development. Scientific Articles of V International Conference.

House, J.S. (1981). Work stress and social support. Englewood Cliffs, NJ: Prentice Hall.

Jang, M., \& Whittemore, R. (2015). The family management style framework for families of children with obesity. The Journal of Theory Construction and Testing, 19(1), 5-14.

Jones, H. M., Al-Khudairy, L., Melendez-Torres, G. J., \& Oyebode, O. (2018). Viewpoints of adolescents with overweight and obesity attending lifestyle obesity 
treatment interventions: a qualitative systematic review. Obesity Reviews, 20(1), 156-169. doi: 101111/obr.12771

Karnik, S., \& Kanekar, A. (2012). Childhood obesity: A global public health crisis. International Journal of Preventive Medicine, 3(1), 1-7.

Kids Count Data Center. (2020). Obesity trends by state.

https://datacenter.kidscount.org/data/tables/99-total-population-by-child-andadultpopulations?loc=1\&loct=1\#detailed/1/any/false/1729,37,871,870,573,869,36,868, $\underline{867,133 / 39,40,41 / 416,417}$

Kitzmann, K.M., Dalton, W.T., Buscemi, J. (2008). Beyond parenting practices: Family context and the treatment of pediatric obesity. Family Relations, 57(1), 13-23

Langford, C.P.H., Bowsher, J., Maloney, J.P., \& Lillis, P. (1997). Social support: A conceptual analysis: Journal of Advanced Nursing. 25(1), 95-100.

Lee, H. (2011). Inequality as and explanation for obesity in the United States. Sociology Compass, 5(3), 215-232

Lee, G., \& Lim, H. (2009). A Spatial Statistical Approach to Identifying Areas with Poor Access to Grocery Foods in the City of Buffalo, New York. Urban Studies, 46(7), 1299-1315. doi: 10.1177/0042098009104567

Lobstein, T., Baur, L., \& Uuay (2004). Obesity in children and young people: A public health crisis. Obesity Reviews. 5(s1), 4-85. https://doi.org/10.1111/j.1467789X.2004.00133.x 
Lohman B, Stewart S, Gundersen C, Garasky S, Eisenmann JC. Adolescent overweight \& obesity: links to food insecurity and individual, maternal, and family stressors. J Adolesc Health 2009; 45: 230- 237.

Maine Health Let's Go. (2020). Children's program. https://mainehealth.org/lets-go

Maine Health Let's Go. (2020). National program. https://mainehealth.org/LetsGo/National-Program

Mistry, K., Minkovitz, C., Riley, A., Johnson, S., Grason, H., Dubay, L., \& Guyer, B. (2012). A new framework for childhood health promotion: The role of policies and programs in building capacity and foundations of early childhood health. American Journal of Public Health. 102(9) 1688-1696.

National Collaborative on Childhood Obesity (NCCOR) (2020). Accelerating progress to reduce childhood obesity. https://www.nccor.org/

National Survey of Children's Health (NSCH). (2017, November 21). The state of childhood obesity. https://stateofchildhoodobesity.org

Office of Disease Prevention and Health Promotion. (2020). Overweight and obesity. Healthy People 2030. https://health.gov/healthypeople/objectives-anddata/browse-objectives/overweight-and-obesity

Oliveria, V., Prell, M., Tiehen, L., \& Smallwood, D. (2018, January). Design issues in USDA's supplemental nutrition assistance program: Looking ahead by looking back. USDA. www.ers.usda.gov 
Ordway, M. R., Sadler, L. S., Holland, M. L., Slade, A., Close, N., \& Mayes, L. C. (2018). A Home Visiting Parenting Program and Child Obesity: A Randomized Trial. Pediatrics, 141(2). doi: 10.1542/peds.2017-1076

Peterson, S.J. \& Bredow, T.S. (2013). Middle range theories: Application to nursing research. 3ed. Wolters Kluwer, Lippincott Williams \& Wilkins.

Rieder, J., Cain, A., Carson, E., Benya, A., Meissner, P., Isasi, C.R., \& Bauman, L.J. (2018). Pilot project integrate community and clinical level systems to address disparites in the prevention and treatment of obesity month ethnic minority inner city middle school students: Lessons learned. Journal of Obesity, 1-15.

Roberts, S.J. (1984). Social support-meaning, measurement, and relevance to community health nursing practice. Public Health Nursing, 1(3), 158-167.

Rogers, V. W., Hart, P. H., Motyka, E., Rines, E. N., Vine, J., \& Deatrick, D. A. (2013). Impact of Let's Go! 5-2-1-0: A Community-Based, Multisetting Childhood Obesity Prevention Program. Journal of Pediatric Psychology, 38(9), 1010-1020. doi:10.1093/jpepsy/jst057

Sahoo, K., Sahoo, B., Bhadoria, A.S., Choudhury, A.K., Sofi, N.Y., \& Kumar, R. (2015). Childhood obesity: Causes and consequences. Journal of Family Medicine and Primary Care. 4(2), 187-192

Schoonjans, F. (2021, May 21). MedCalc's Fisher exact probability calculator. MedCalc. https://www.medcalc.org/calc/fisher.php. 
Simmonds, M., Llewellyn, A., Owen, C. G., \& Woolacott, N. (2015). Predicting adult obesity from childhood obesity: a systematic review and meta-analysis. Obesity Reviews, 17(2), 95-107. https://doi.org/10.1111/obr.12334

Strauss RS, Knight J. Influence of the home environment on the development of obesity in children. Pediatrics. 1999 Jun;103(6):e85. doi: 10.1542/peds.103.6.e85. PMID: 10353982.

Tilden, V.P., \& Weinert, S.C. (1987). Social support and the chronically ill individual. Nursing Clinics of North America, 22(3), 613-620.

United States Census Bureau. (2020, September 15). Income and poverty in the United States: 2019. https://www.census.gov/library/publications/2020/demo/p60$\underline{270 . h t m l}$

USDA. (2020). Food security and nutrition assistance. https://www.ers.usda.gov/dataproducts/ag-and-food-statistics-charting-the-essentials/food-security-andnutritionassistance/\#: : $\operatorname{text}=\operatorname{In} \% 202019 \% 2 \mathrm{C} \% 2089.5 \% 20$ percent $\% 20$ of, than $\% 202018 \% 2$ $\underline{0(11.1 \% 20 \text { percent })}$.

USDA. (2020). Guide to measuring household food security. https://www.fns.usda.gov/guide-measuring-household-food-security-revised-2000

Wang, Y. (2011). Disparties in pediatric obesity in the United States. Advances in Nutrition. 2(1) 23-31. https://doi.org/10.3945/an.110.000083Appendices 
Wolch, J., Jerrett, M., Reynolds, K., McConnell, R., Chang, R., Dahmann, N., Brady, K., Gilliland, F., Su, J. G., \& Berhane, K. (2011). Childhood obesity and proximity to urban parks and recreational resources: A longitudinal cohort study. Health \& Place, 17(1), 207-214. https://doi.org/10.1016/j.healthplace.2010.10.001 
Appendix A

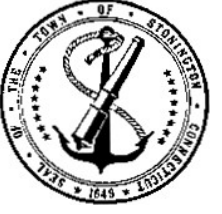

\section{Town of Stonington Department of Human Services}

166 South Broad Street

Recreation O Senior Serviccs O

September 22, 2020

Institutional Review

Board at Rhode

Island College 600

Mount Pleasant

Ave Providence, RI

02908

To Whom It May Concern,

Michelle M. Bull, has permission to conduct a study working with families on healthy living behaviors and identification of food resources this fall (2020) at Stonington Human Services.

Thank you,

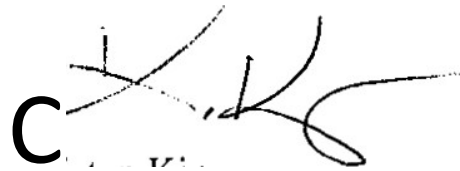

Kristen King

Youth \& Family Services Administrator

Phone: (860) 535-5015Fax: (860) $\underline{599-8290}$
Pawcatuck, Connecticut 06379

Social Services O Youth \& Family Services 


\title{
Appendix B
}

\section{CONSENT DOCUMENT \\ Rhode Island College}

\author{
Evaluating Resource Nurse Assistance to Families
}

You are being asked along with your family to be part of a project evaluating the role of a resource nurse working with families to promote resources surrounding food security and healthy living. The information being collected will be evaluated to promote the role of the nurse in working with families in a community setting regarding food resources needed for healthier living. Participation in this project is voluntary and it is anticipated that you would be involved for eight weeks' time this fall.

Please read this form and ask any questions that you have before choosing whether to participate.

Michelle Bull RN, a doctoral student in Nursing Studies, is doing this project in collaboration with the faculty advisor Lynn Blanchette PhD, a professor at Rhode Island College.

\section{Why this Project is Being Done (Purpose(s)}

We are doing this project to evaluate the role of the resource nurse working with families utilizing resources in the community as a method to increase healthier behaviors and food security. The research part of the program is to evaluate the nursing intervention regarding providing resources and access to food and healthier living habits regarding your family.

\section{What You Will Have to Do (Procedures)}

If you choose to be in the project, we will ask you to:

- First, you will be asked survey questions about your access to food. The questions ask basic things about yourself and your family like your age, your highest level of school, how many children you have, how much money the family is making, and other questions related to food resources. This will take about 10 minutes. 
- Second, you'll talk with me and I will give you information on a program called Let's Go! 5,2,1,0. The program provides daily tips on how to complete healthy habits. You will be asked to follow this program during the study. You will be given a form to fill out weekly and a time will be arranged that the nurse can speak to you weekly regarding your progress with the program.

- Third, you will be given information about the Yellow Farm House, an educational center in town that will be available to you and your family during the study. You and your family will have access to virtual cooking classes during the program.

- Fourth, you will talk with me about setting a time for delivery of food to your home that will be provided free of charge from Stone Acres Farm in Stonington weekly during the program. You may also be able to pick the food up directly from Stone Acres farm if you wish.

- Last, at the end of the program, you will be asked to answer the same survey that you did in the beginning of the program.

\section{Risks or Discomforts}

You may find that answering some questions on the food security access survey is upsetting. We think it would be similar to the kinds of things you talk about with family and friends. You can skip any questions you don't want to answer, and you can stop the interview at any time. Kristen King, Youth and Family Services Director at the Department of Human Services in Stonington at 860-535-5015, is available at any point during the program if you wish to reach and speak to someone regarding any negative feelings that come up during the duration of the program. Your identities will be concealed regarding participation in the program.

\section{Benefits}

By consenting to be in this program, you and your child will have access to a nurse weekly. The nurse will be able to help with in regards to resources needed to maintain a healthy lifestyle surrounding nutrition. A nutritionist will be available to you and your child as needed on referral by the nurse. Each week during the eight-week program, your family will receive weekly produce from Stone Acres Farm. The produce can be arranged to be picked up locally by you or delivered at your request by the nurse.

You and your child will receive a membership to the Dandelion Club at the Yellow Farm House at the beginning of the program and through the duration of program regardless of completion. Membership to the Dandelion Club includes unlimited access to both virtual and onsite programs at Stone Acres Farm, on farm experiences and small group cooking classes for all ages. 


\section{$\underline{\text { You Will Be Paid (Compensation) }}$}

As a way to thank you for your time, you will receive a $\$ 25$ gift card to Stop and Shop at the completion of the program. If you chose not to finish the program, your gift card will be prorated to the time that you completed in the program. For example, if you completed four weeks out of eight weeks, you will get \$15 gift card.

\section{Deciding Whether to Be in the Project}

Being in the project is your choice to make. Nobody can force you to be in the project. You can choose not to be in the project, and nobody will hold it against you. You can change your mind and quit the project at any time, and you do not have to give a reason. If you decide to quit later, nobody will hold it against you.

\section{How Your Information will be Protected}

We will take several steps to protect the information you give us so that you cannot be identified. Instead of using your name, your information will be given a code number. The program outcomes will be summarized and shared in reports for learning purposes in the future.

\section{Who to Contact}

You can ask any questions you have now. If you have any questions later, you can contact Michelle Bull at 850-388-7703 or by email at mbull 8557@email.ric.edu.

You will be given a copy of this form to keep. 


\section{Statement of Consent}

I have read and understand the information above. I am choosing to be in the program

"Providing Resource Nurse Assistance to Families". I can change my mind and quit at any time, and I don't have to give a reason. I have been given answers to the questions I asked, or I will contact the researcher with any questions that come up later. I am at least 18 years of age.

Print Name of Participant:

Signature of Participant: Date:

Name of Researcher Obtaining Consent: Michelle M. Bull, MSN, RN 


\section{Appendix C}

October 30,2020

1-860-388-7703

Mbull_8557@ric.email.edu

Hello,

I am Michelle Bull, a current Doctor of Nursing Practice student at Rhode Island College in Providence, RI. I have been a pediatric nurse for twenty years and teach at the Community College of Rhode Island in the nursing department.

I have been conducting research on family wellness and food security this fall. I will be working with families this fall in Stonington on implementing a program called Let's Go! $5,2,1,0$. The program will be run over a course of eight to ten weeks. The program focuses on consuming five fruit and vegetables a day, two hours or less of screen time, one hour of physical activity and zero sugary beverages. The goal of the program is to instill healthier habits in families with children. Additionally, we have collaborated with the Yellow Farm House Education Center and Stone Acres Farm in Stonington. Your family will be given a weekly produce delivery with recipe cards during the duration of the program. Your name has been given to Laura Jackson at the Yellow Farm House. In addition, you and your children given a membership to the Dandelion Club at the Yellow Farm House, in which they will be included in weekly virtual cooking classes and be able to participate in farm related activities throughout the year if you wish. I have included information regarding the Yellow Farm House in the packet. You will be given information on how to register for classes there. It will be free of charge. You will be asked to fill out weekly progress reports and how you are following the Let's Go! 5,2,1,0 plan. I have attached the information on the program in the packet. We will review these questions weekly over the phone.

My services will be available to assist with resources needed during the program. There will also be licensed nutritionist available as needed during the program. We will ask for your phone number and email contact so we can do weekly check ins to see how the program is going and if we can do anything to assist to make it better.

I'm looking forward to working with your family this fall. I will ask that you provide consent for my time with you and the program intervention. The consent forms are included in the packet. Participation is voluntary and free of charge. As a thank you for your completion of the program, a $\$ 25$ gift card to a local grocery store will be given to each family. I will be readily available when needed during the program time. My goals are to work with you starting in October through December.

Sincerely, 
Appendix D

Intake Sheet

Stonington Human Services Resource Nurse Study

Family Name:

Head of household name or primary contact person:

Number of members in family above 18 years old and names:

Number of members in Family under 18 years old and names:

Address:

Phone number:

Best time to reach you:

\section{Comments}




\section{Appendix E}

\section{Eat at least five fruits \& vegetables a day.}

\section{Every Day!}

5 or more servings of fruits \& vegetables 2 hours or less recreational screen time 1 hour or more of physical activity 0 sugary drinks, more water \& low fat milk

A diet rich in fruits and vegetables provides vitamins and minerals, important for supporting growth and development, and for optimal immune function. Most fruits and vegetables are low in calories and fat, making them a healthy choice anytime. They may also contain phytochemicals (fight-o-chemicals) that work together with fiber to benefit your health in many ways. Different phyotchemicals are found in different fruits based on their color-that's why it's important to put a rainbow on your plate.

\section{TRY IT!}

$\star \quad$ Try the three bite rule. Offer new fruits and veggies different ways and try at least three bites each time-it can take 7 to 10 tries before you like a new food.

$\star$ Many fruits and veggies taste great with a dip or dressing. Try a low fat salad dressing with yogurt or get protein with peanut butter.

$\star$ Make a fruit smoothie with low fat yogurt.

\section{IT!}

$\star$ Add them to foods you already make, like pasta, soups, casseroles, pizza, rice, etc.

$\star$ Add fruit to your cereal, pancakes, or other breakfast foods.

$\star$ Be a good role model for your family and have at SLICE IT!

least one veggie at every meal.

\section{WHAT IS A}

SERVING? $\star$ Wash and chop veggies and fruits so they are ready to grab and eat.

^ Most people prefer crunchy foods over mushy ones.

Enjoy them fresh or lightly steamed.

Do not underestimate the importance of family mealtime; take 10-15 minutes to sit down together.

$\star$ Get your family involved with meal planning.
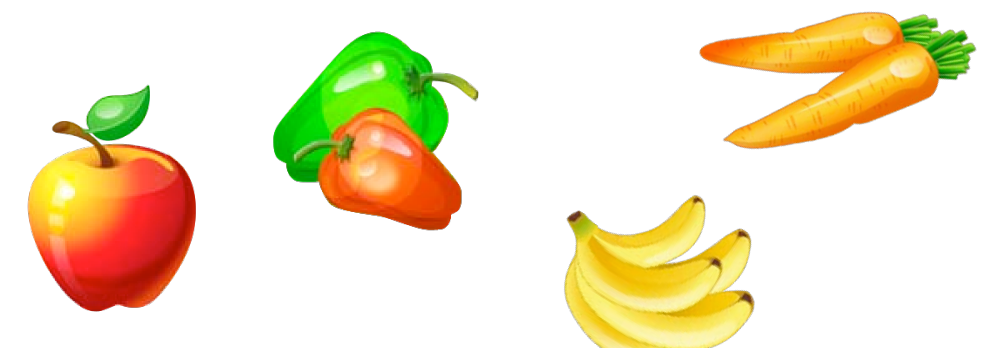

FAMILY MEALTIME

Adults

A whole fruit the size of a tennis ball

$1 / 2$ cup of chopped fruit or veggies

1 cup of raw, leafy greens

$1 / 4$ cup of dried fruits

Kids

Size of the palm of their hand 


\section{PUT LIMITS ON JUICE}

- Juice products labeled "-ade," "drink," or "punch" often contain 5\% juice or less. The only difference between these "juices" and soda is that they're fortified with Vitamin C. Always try to choose whole fruits over juice.

- If you choose to serve juice, buy $100 \%$ juice.

- Make changes slowly by adding water to your child's juice.

- Try mixing seltzer with a small amount of juice.

- Each day, juice should be limited to: 4-6 ounces for children 1-6 years old; 8-12 ounces for children 7-18 years old; Children 6 months and under should not be given juice

\section{OFFER NON-FOOD REWARDS}

Have your family put together a list of fun, nonfood rewards that don't cost much. Post it where the whole family can see it. Examples: playing outdoors, a family game night, going to a ball game, buying a new book, extra reading time before bed.

\section{BE A ROLE MODEL:}

Snack on fruits and veggies Have the family help plan meals 


\section{Limit recreational TV or computer use to two hours or less.}

$\Rightarrow \quad$ Screentime includes TV, computer, Playstation, and Gameboy. All are important to limit.

$\Rightarrow \quad$ Watching TV is associated with more snacking and increased obesity.

$\Rightarrow \quad$ Too much TV has been linked to lower reading scores and

5210 Every Day!

5 or more servings of fruits \& vegetables

2 hours or less recreational screen time

1 hour or more of physical activity

0 sugary drinks, more water $\&$ low fat milk attention problems.

$\Rightarrow \quad$ Healthy Screen Time:

$\propto \quad$ No TV/computer under the age of 2

$\propto \quad$ No TV/computer in the room the child sleeps

$\propto$ One hour of educational TV/computer time between ages 2 and 5

$\propto$ After the age of 5, 2 hours or less

LIFE IS LOTS MORE FUN WHEN YOU JOIN IN! TRY THESE ACTIVITIES INSTEAD OF WATCHING TV.

Walk, run, or jog

Put together a puzzle

Go on a nature hike

Read a book or magazine

Spend time catching up with your family

Charades
Ride a bike

Start a journal

Go to the library

Turn on the music and dance

Explore gyms in your community

Rollerblade

Take your kids to the park or beach

Sled, ski, or snowshoe Play board games 


\section{TAME THE TV AND COMPUTER!}

$\checkmark$ Participate - keep TVs, computers, DVD players, and video games out of your child's room.

$\checkmark$ Having the TV in a common room makes watching a family activity.

$\checkmark$ Watch TV with your child and discuss the program. Ask them questions and express your views.

$\checkmark$ This will also let you know what your children are watching.

\section{SET LIMITS - KNOW HOW MUCH TV YOUR CHILD IS WATCHING.}

$\checkmark$ Set some basic rules such as no TV or computer before homework or chores are done.

$\checkmark$ Do not watch TV during mealtime.

$\checkmark$ Use a timer. When the bell rings its time to turn off the TV or eliminate TV time during the week.

\section{HELP YOUR CHILD PLAN TELEVISION VIEWING IN ADVANCE.}

$\checkmark \quad$ Keep books, magazines, and board games in the family room.

$\checkmark$ Make a list of fun activities to do instead of being in front of a screen.

$\checkmark$ Set family guidelines for age-appropriate shows.

\section{BE A ROLE MODEL.}

Because children model behavior, set a good example with your own TV viewing habits. Avoid watching programs containing adult content when your child is in the room or nearby. Have the family help with dinner. It gets them involved and shows them helping is important. Put on music and let the kids dance. 


\section{Get one hour or more of physical activity every day.}

One hour of moderate physical activity physical activity means doing activities where you breathe hard like hiking or dancing. 20 minutes of vigorous physical activity means doing activities where you sweat, like running, aerobics, or basketball.

\section{Every Day!}

5 or more servings of fruits \& vegetables

2 hours or less recreational screen time

1 hour or more of physical activity

$\mathbf{0}$ sugary drinks, more water \& low fat milk

\section{Physical activity...}

Makes you feel good

Helps you keep a healthy weight

Makes your heart happy

Makes you stronger

Makes you flexible

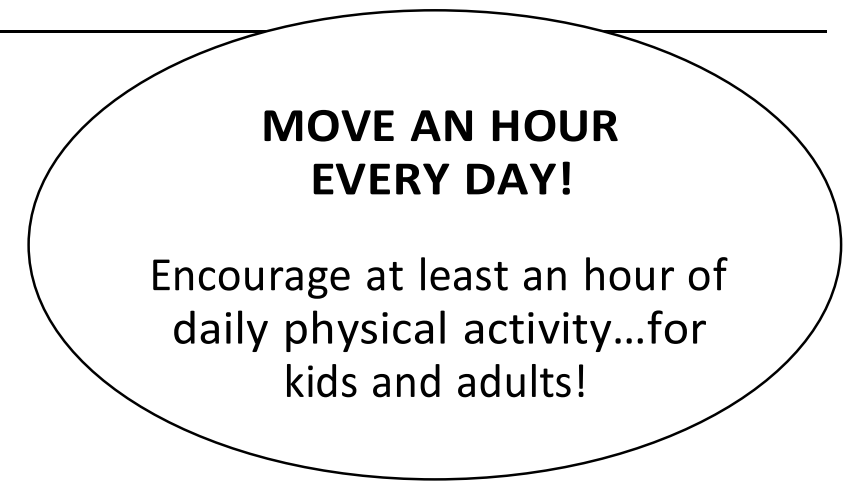

\section{USE PHYSICAL ACTIVITY AS A REWARD}

$\checkmark$ Write a short list of good behaviors on a chart. Mark the chart with a star every time you see the good behavior.

$\checkmark$ After your child has earned a small number of stars, give him or her a reward.

$\checkmark$ Give your child extra play time before or after meals as a reward for finishing homework. Avoid giving your child extra time in front of the screen as a reward.

$\checkmark$ Choose fun, seasonal activities.

$\checkmark$ Encourage your child to try a new sport or join a team.

\section{LET PHYSICAL ACTIVITY BE FREE AND FUN!}

$\checkmark$ Take a walk with your family

$\checkmark$ Play with your pet

$\checkmark$ Play tag

$\checkmark$ Take a bike ride (remember to wear your helmet)

$\checkmark$ Turn on music and dance
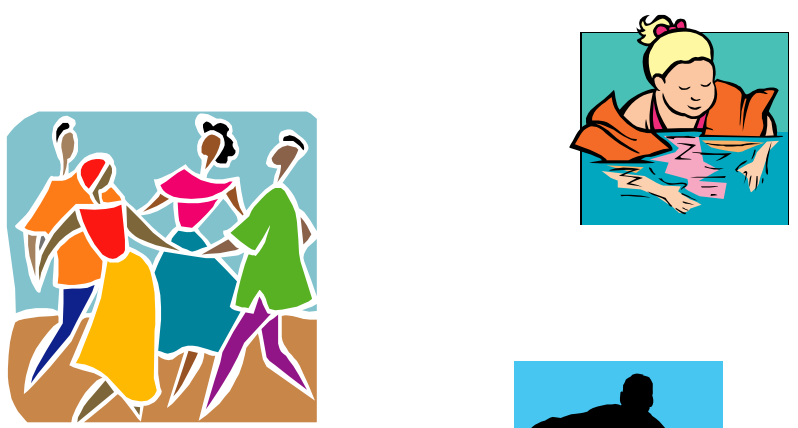

$\checkmark$ Jump rope

$\checkmark$ Play Frisbee

$\checkmark$ Take the stairs

$\checkmark$ Park the car at the end of the parking lot

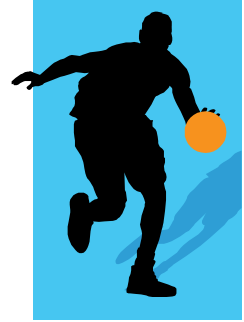

$\checkmark$ Make snow angels 


\section{MAKE PHYSICAL ACTIVITY EASIER.}

Make gradual changes to increase your level of physical activity. Incorporate physical activity into your daily routines. Try tracking the level of your physical activity using a pedometer.

Turn off the TV and computer and keep them out of the bedroom.
Limit recreational computer time.

Choose toys and games that promote physical activity.

Encourage lifelong physical activity by incorporating physical activity into your routine.

Keep physical activity fun!!

BE A ROLE MODEL.

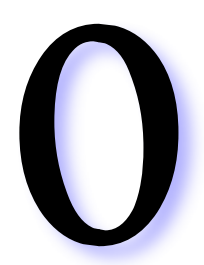

\section{Use a pedometer. Take a walk after dinner. \\ Drink less sugar. Try water \& low fat milk instead of soda and drinks with lots of sugar.}

Soda has no nutritional value and is high in sugar. Just nine ounces of soda has 110-150 empty calories. Many sodas also contain caffeine, which kids don't need. Energy drinks are NOT sports drinks and should never replace water during exercise.

\section{Every Day!}

5 or more servings of fruits \& vegetables

2 hours or less recreational screen time

1 hour or more of physical activity

0 sugary drinks, more water $\&$ low fat milk

\section{ENCOURAGE LOW FAT MILK INSTEAD OF SUGAR-SWEETENED DRINKS.}

According to the national dairy council:

$\checkmark$ Children ages 4-8 years old should be consuming three 8-ounce glasses of milk or other dairy each day.

$\checkmark$ Children ages 9-18 years old should be consuming four and a half 8-ounce glasses of milk or other dairy each day.

The recommendation is that children over the age of two drink low fat milk. Gradually make the change from whole milk to low fat milk.

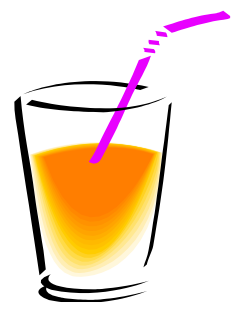

\section{WATER IS FUEL FOR YOUR BODY:}


Water is the most important nutrient for active people. Keep bottled water or a water bottle on hand.

Between $70-80 \%$ of a child's body is made up of water.

When you exercise, you sweat, and when you sweat you LOSE water and minerals - it is important to replace the water you lose when you sweat.

Water is the \#1 thirst quencher!
Add fresh lemon, lime, or orange wedges to water for some natural flavor.

Fill a pitcher of water and keep it in the fridge.

Drink water when you're thirsty. It's the best choice.

Cut back slowly on sugar-sweetened drinks.

Replace soda with water, instead of other sugarsweetened beverages, such as juice or sports drinks.

\section{PUT LIMITS ON JUICE}

$\checkmark$ Juice products labeled "-ade," "drink," or "punch" often contain 5\% juice or less. The only difference between these "juices" and soda is that they're fortified with Vitamin C.

$\checkmark$ Always try to choose whole fruits over juice.

$\checkmark \quad$ If you choose to serve juice, buy $100 \%$ juice.

$\checkmark$ Each day, juice should be limited to:

○ 4-6 ounces for children 1-6 years old $\circ$ 8-12 ounces for children 7-18 years old $\circ$ No juice for children 6 months and under

Make changes slowly by adding water to your child's juice.

$\checkmark$ Suggest a glass of water or low fat milk instead of juice.

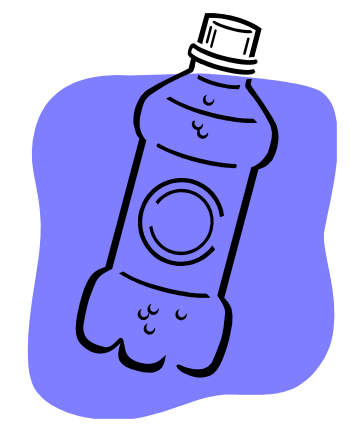

\section{BE A ROLE MODEL:}

Grab a glass of water instead of soda. Try mixing seltzer with a small amount of juice.
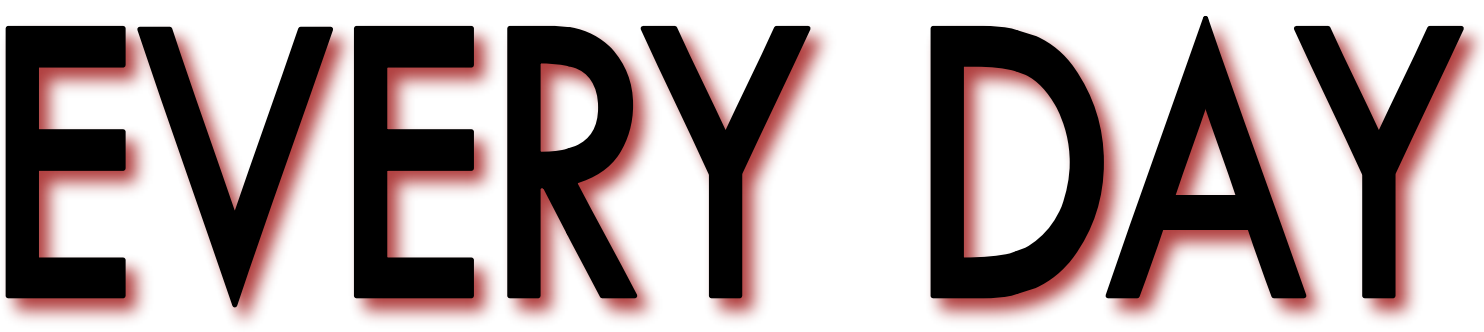
Eat fruits \& vegetables at least 5 times

$\square \quad$ Eat a fruit or vegetable at every meal.

$\square$ Eat a healthy breakfast \& include fruit on your cereal.

$\square$ Wash \& chop them ahead of time so they are ready to eat.

Limit TV \& other screen time to 2 hours or less

$\square \quad$ Keep the TV out of your bedroom.

$\square$ Turn off the TV and enjoy a family meal together.

$\square$ Plan what you want to watch.

\section{Enjoy 1 hour or more of active play}

$\square$ Play outside and have fun with your friends.

$\square \quad$ Take a family walk after dinner. $\square$ Walk while talking on your cell phone.

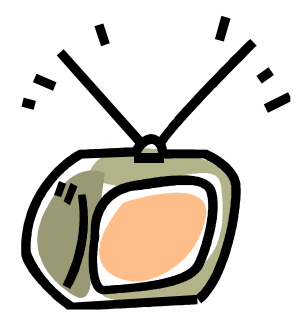

Restrict soda \& sugar-sweetened drinks 
$\square$ Instead, encourage water \& 2-4 servings of fat free milk.

$\square$ Limit fruit juice to half cup or less. $\square$ Read drink labels before you buy them.

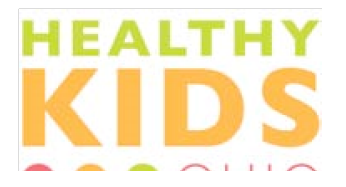




\section{Appendix F}

\section{Weekly Survey}

Family Name Number:

Week:

Each week during the program you will be asked the following questions. The resource nurse will call you at a scheduled time to review the questions below. Please rate yourself as directed below.

1. Overall, how well were you able to follow the guidelines of Let's Go! 5,2,1,0? On scale of $0-10$, with 0 meaning you did not follow it at all and 10 meaning that you followed it well. Please circle the number below.
0 1
23
$\begin{array}{lll}4 & 5 & 6\end{array}$
$\begin{array}{lll}7 & 8 & 9\end{array}$
10

2. If you rated yourself less than 5 in the above scale, what stopped you from following the guidelines?

3. Did you cook and consume the food that was delivered to you this week? Yes or No

If the answer is no, please explain why?

4. Did you participate in the virtual cooking class by the Yellow Farm House this week? Yes or No

If the answer is no, please explain why? 
